
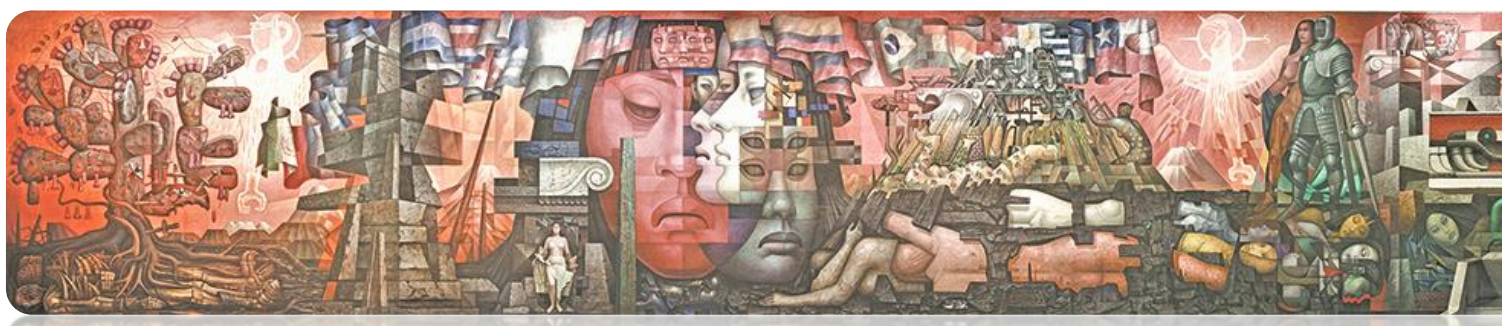

Rev. Hist., N²8, vol. 2, Julio-Diciembre 2021: 392-437

ISSN 0717-8832

https://doi.org/10.29393/RH28-38AAMD20038

\title{
Agenda, alternativas y pensiones en la vieja democracia chilena: siglo XIX hasta la década de 1970*
}

Agenda, alternatives, and pension in the old Chilean democracy: nineteenth century until

$1970 \mathrm{~s}$

\author{
Mauricio Olavarría Gambi ${ }^{* *}$ \\ Daniel Ahumada Benítez ${ }^{* * *}$
}

\section{RESUMEN}

Haciendo converger el análisis histórico y el de la política de las políticas públicas, este artículo examina la trayectoria del esquema de pensiones chileno desde el siglo XIX hasta principios de la década de 1970. El trabajo se focaliza en los procesos de formulación de políticas de pensiones - tanto aquellas iniciativas de alta significación que lograron ser aprobadas, como las que fallaron en ello -, con el propósito de identificar las características del proceso de formulación de políticas públicas en la vieja democracia chilena y el rol desempeñado por actores del sistema político en ello. La información analizada proviene de archivos de los poderes públicos, prensa de época, literatura académica y entrevistas a personajes claves. El artículo concluye que el proceso de formulación de políticas públicas de la vieja democracia chilena era elitario - donde el Presidente de la República era el actor protagónico -, con alta incidencia tecnocrática y en el que la distribución de competencias entre los poderes ejecutivo y legislativo, e interacciones entre los actores de poder, permitieron crear y desarrollar el régimen de pensiones, pero

\footnotetext{
* Nuestros reconocimientos a Universidad de Santiago de Chile. Agradecimientos a DICYT 032052OG, Vicerrectoría de Investigación, Desarrollo e Innovación. Agradecimientos también a dos árbitros anónimos por sus comentarios y sugerencias.

** Mauricio Olavarría Gambi es Doctor (Ph.D) en Policy Studies por la Universidad de Maryland at College Park y Profesor Titular de la Universidad de Santiago de Chile. Área de Investigación: Políticas Públicas. ORCID: https://orcid.org/0000-0001-5997-2873. Correo Electrónico: mauricio.olavarria@usach.cl

*** Daniel Ahumada Benítez es Magister en Historia Económica por la Universidad de Santiago de Chile y Estudiante de Doctorado en Historia de la Pontificia Universidad Católica de Chile. Área de Investigación: Historia Económica. ORCID: https://orcid.org/0000-0001-6793-1094.Correo Electrónico: dlahumada@uc.cl
} 
también permitieron que se orientara a la satisfacción de intereses particulares, lo que luego impidió la aprobación de reformas que buscaban imprimirle mayor racionalidad a la acción del Estado, con la finalidad de lograr mayores niveles de equidad e integralidad en este ámbito.

Palabras Claves: Pensiones, Chile, Formulación de Políticas Públicas, Previsión Social, Reforma Previsional, Seguro Social.

\section{ABSTRACT}

Making to converge the historical analysis and that of the politics of public policy, this article examines the trajectory of the Chilean pension scheme from the $19^{\text {th }}$ century to the 1970 s. The work focuses on the formulation process of the pension policy - both the highly significant that gained approval as well as those that failed in it -, with the purpose of identifying the characteristics of the policy formulation process of the old Chilean democracy and the role played by actors of the political system in it. Information comes from public archives, press, academic literature, and interviews to key actors. The article concludes that the policy formulation process of the old Chilean democracy was elitist - where the President was the protagonist -, with a high technocratic incidence and with a distribution of competence between the executive and legislative branches that favored the creation and development of the pension scheme. However, this also favored that the pension scheme was oriented to the satisfaction of interests, which later prevented reforms that sought to provide a greater rationality to the State activity and achieve higher levels of equity and integrality in this area

Key words: Pensions, Chile, Policy Formulation, Social Security, Pension Reform, Social Insurance

Recibido: mayo 2021

Aceptado: noviembre 2021

\section{Introducción}

Reiteradamente se plantea que el esquema previsional chileno se estableció como tal en 19241925, con la aparición de las Cajas del Seguro Obligatorio, de Empleados Públicos y Empleados Particulares ${ }^{1}$, pero poca atención se ha prestado a los mecanismos de pensiones que se fueron

\footnotetext{
${ }^{1}$ Arellano, José Pablo. 1988. Políticas Sociales y Desarrollo. Chile 1924-1984, Santiago, Chile, CIEPLAN; Castiglioni, Rossana. 2000. Welfare State Reform in Chile and Uruguay: Cross-class coalition, elite ideology, and veto players, XXII Congress of the Latin American Studies Association, Miami, March 16-18; Castiglioni, Rossana. 2015. Building and sustaining social protection: cross-class coalition, elite responses, and party politics in Chile and Uruguay (1970-1973), Working Paper №407, Kellogg Institute for International Studies, University of Notre Dame; Larrañaga, Osvaldo. 2010. "Las Nuevas Políticas de Protección Social en Perspectiva Histórica”, en Larrañaga, Osvaldo y Contreras, Dante (eds.), Las Nuevas Políticas de Protección Social en Chile, Santiago, Uqbar, pp. 13-42; Mesa-Lago, Carmelo. 1985. EI Desarrollo de la Seguridad Social en América Latina, Estudios e Informes de la CEPAL №43, Santiago, Naciones Unidas; Poblete, Moisés. 1949. El derecho del trabajo y la seguridad social en Chile, Santiago, Editorial Jurídica de Chile; Wallich, Christine. 1981. Social security and savings mobilization. A case study of Chile, Domestic Finance Studies N67, Washington D.C., The World Bank; Wallich, Christine. 1983. Savings mobilization through social
} 
estableciendo con anterioridad a ese momento. Los análisis de reformas se han concentrado en las de 1952, que instauró el régimen de reparto, y la de 1979, que configuró el esquema de capitalización individual vigente desde 1980, descuidando el examen de aquellas propuestas de reformas que no lograron materializarse, como las de 1955, 1962 y 1968 . Junto a ello, es dable anotar que los estudios sobre los temas previsionales han tendido a concentrarse en análisis económicos y en exposiciones historiográficas que se aproximan al tema de pensiones, quedando un gran espacio analítico no abordado respecto de los procesos de formulación de política pública que fueron constituyendo los mecanismos previsionales, sus modificaciones y los intentos fallidos de reforma.

Con ello, episodios de formulación o reforma de los esquemas jubilatorios imperantes en variados momentos históricos han quedado fuera de los análisis acerca del desarrollo de la previsión en Chile. Así, preguntas como las siguientes han quedado inexploradas: ¿Por qué el esquema de pensiones ha sido como ha sido? ¿Por qué algunos procesos de formulación de políticas públicas resultaron exitosos, estableciéndolo o reformándolo y por qué otros intentos de reforma fracasaron? Este artículo intenta responder esas preguntas haciendo converger el análisis histórico con el análisis político de políticas públicas y, más precisamente, con el análisis de los procesos de formulación de políticas públicas. Así, el foco analítico de este trabajo son los diversos procesos claves de formulación o reforma de políticas públicas en el ámbito de pensiones, que se desarrollaron hasta la década de 1970, y que, en conjunto, configuran la trayectoria de la vieja democracia chilena en esta área de actividad del Estado.

La seguridad social chilena es considerada una de las pioneras en América Latina ${ }^{2}$, tanto por su temprano surgimiento, como por la cobertura que ha alcanzado ${ }^{3}$, pero también ha sido objeto de atención, por la fragmentación, alto costo e inequidad en la distribución de beneficios que exhibió ${ }^{4}$. Así, el análisis de la evolución de la seguridad social chilena, en una perspectiva integradora de los momentos claves, aporta información para poder comprender por qué este evolucionó del modo en que lo hizo, quienes fueron los actores claves en cada momento crítico,

security. The experience of Chile during 1916-77, World Bank Staff Working Papers N553, Washington D.C., The World Bank.

2 Mesa-Lago. 1985, El Desarrollo; Wallich. 1981, Social security; Wallich. 1983, Savings mobilization; Poblete. 1949, El derecho; Garretón, Manuel Antonio y Morales, Eduardo. 1976. Políticas sociales y papel redistributivo del Estado en América Latina. Antecedentes y consideraciones preliminares, Documento de Trabajo FLACSO, Santiago, FLACSO. ${ }^{3}$ Arellano. 1988, politicas sociales; Wallich. 1981, Social security; Wallich. 1983, Savings mobilization; Mesa-Lago, Carmelo. 1978. Social Security in Latin America. Pressure Groups, Stratification, and Inequality, Pittsburgh, University of Pittsburgh Press; Mesa-Lago. 1985, El Desarrollo.

${ }^{4}$ Mesa-Lago. 1985, El Desarrollo; Arellano. 1988, políticas sociales; Aninat, Eduardo. 1971. Nuevas Alternativas para el Sistema Chileno de Seguridad Social, Documento CEPLAN №6, Santiago, Centro de Estudios de Planificación Nacional, Universidad Católica de Chile; Larrañaga. 2010, "Las nuevas"; Wallich. 1981, Social security; Wallich. 1983, Savings mobilization. 
qué factores y circunstancias socioeconómicas y políticas determinaron el curso de esa evolución y cómo ellos fueron procesados por el sistema político.

Dada su condición de pionero, el análisis de las circunstancias que fueron moldeando la previsión chilena resulta de interés tanto para trazar la trayectoria evolutiva que ha tenido, la configuración y desarrollo de las propuestas de reforma, como para que estudios posteriores puedan contrastar sus conclusiones con lo ocurrido en países similares. Pero, también resulta de interés para caracterizar el proceso de la política pública, el rol que cumplieron actores institucionales e informales y el contexto en que estos procesos ocurrieron, de modo de poder establecer si este caso presenta coincidencias con las características que otros estudios han identificado para diversos casos de formulación de política pública.

El artículo se centra en la convergencia de las perspectivas del institucionalismo histórico y del procesalismo institucional para construir la narrativa que identifica los momentos claves de la evolución y los procesos que en ellos se desarrollaron. En ello, acude a registros históricos para identificar los momentos claves y el desarrollo de los acontecimientos, a la vez que aplica el enfoque de las corrientes múltiples para desentrañar las circunstancias y factores que incidieron en el desenvolvimiento del proceso de la política pública y sus resultados en cada uno de los momentos. El trabajo analiza evidencia constituida por situaciones y circunstancias que se desataron dentro de la institucionalidad del Estado ${ }^{5}$, con el propósito de comprender los procesos de toma de decisiones en este espacio de política pública. Así, este trabajo es un análisis de política pública que recoge información histórica para trazar la trayectoria que siguió la previsión en la vieja democracia chilena.

El trabajo que se presenta a continuación es un estudio de caso, dado que analiza un fenómeno de la vida real que transcurre a través del tiempo ${ }^{6}$; es explicativo, en tanto busca identificar los elementos concretos -y sus vínculos- que llevaron a establecer el sistema previsional chileno y los resultados de reformas exitosas y fallidas; y es comparativo, a la vez, en cuanto analiza varios procesos de formulación de políticas públicas -en distintos momentos - para identificar regularidades y características comunes o diferentes entre ellos. Es, también, interdisciplinario en tanto vincula el conocimiento histórico con el análisis de política pública para agregar comprensión a la evolución de la política previsional durante la vieja democracia chilena. La unidad de análisis es el proceso de formulación de política pública, esto es el

\footnotetext{
${ }^{5}$ Durante el siglo XIX y principios del XX, se desarrollaron iniciativas de los propios trabajadores de auxilio y protección social, sin vinculación al Estado. Fueron las Sociedades de Socorros Mutuos, Mutuales y similares, que, en algunos casos consideraron jubilaciones, y que conformaron el panorama desde el que luego se formalizaría un esquema de previsión social del cual no solo serían beneficiarios los empleados públicos. Para una revisión respecto a lo que se ha escrito sobre el tema ver: Venegas, Fernando y Grez, Sergio. 2021. "Historiografía del mutualismo chileno, 1853-1990: análisis crítico y nuevas perspectivas", en Revista Izquierdas, N50, Santiago, pp. 1 - 30.

${ }^{6}$ Gerring, John. 2009. "The Case Study: What It Is and What It Does", in Goodin, Robert (ed.), The Oxford Handbook of Political Science, New York, Oxford University Press, pp.1133-1165.
} 
conjunto de "intercambios complejos entre actores políticos a través del tiempo" 7 cuyo resultado se expresa en esfuerzos exitosos o fallidos por establecer o reformar una política pública.

La información con la que se ha trabajado proviene de fuentes primarias, como informes oficiales de organismos públicos, mensajes presidenciales, mociones parlamentarias, discusiones y debates ocurridos en el Congreso, y fuentes secundarias, como aquellas expuestas en la prensa, medios de divulgación de organizaciones de la sociedad civil y publicaciones académicas. El estudio también ha aplicado entrevistas en profundidad a actores que participaron en algunos de los procesos de reforma señalados, prepararon informes o que los estudiaron en su oportunidad.

El plan de exposición contempla la siguiente organización. Luego de esta introducción, la siguiente sección expone la perspectiva conceptual que adopta el artículo. Enseguida se exponen los hitos centrales que fueron constituyendo el desarrollo de la seguridad social chilena y que configuran la evidencia recogida sobre los procesos políticos que le fueron dando forma durante la vieja democracia chilena. A continuación, se expone una discusión acerca de los alcances e implicancias que surgen de la revisión de esa evidencia.

\section{Sobre Institucionalismo y procesalismo}

El foco analítico del proceso de formulación de política pública es el cambio de política pública, ya sea a través del estudio del surgimiento de una intervención en un ámbito donde el Estado no se había hecho presente o de la reforma de una en operación. A esta perspectiva, Barzelay y Gallego la denominaron "procesalismo institucional" y la caracterizaron como una "aproximación distintiva para explicar el cambio institucional y de política pública" 8 . Convergentemente, para el institucionalismo histórico el cambio institucional y de política pública es el producto de cambios en las ideas sostenidas por los actores, en el que el concepto de idea hace referencia a soluciones creativas a problemas de acción colectiva ${ }^{9}$.

A su vez, el enfoque de corrientes múltiples es un análisis con perspectiva histórica de procesalismo institucional aplicado al estudio de casos de formulación o cambio de política pública en un país ${ }^{10}$. Este enfoque prevé que habrá más probabilidades de surgimiento de una nueva política pública cuando un problema es reconocido, cuando hay una alternativa posible

\footnotetext{
7 Stein, Ernesto, Tommasi, Mariano, Echeberría, Koldo, Lora, Eduardo y Payne, Mark (coors.). 2006. La política de las políticas públicas. Progreso económico y social en América Latina, Washington DC, Banco Interamericano de Desarrollo.

8 Barzelay, Michael \& Gallego, Raquel. 2006. “From 'New Institutionalism' to 'Institutional Processualism': Advancing Knowledge about Public Management Policy Change", in Governance, vol. 19, № 4, Oxford, pp. 532.

${ }^{9}$ Steinmo, Sven. 2008. "What is Historical Institutionalism", in della Porta, Donatella \& Keatings, Michael (eds.), Approaches in Social Sciences, Cambridge, UK, Cambridge University Press.

${ }^{10}$ Barzelay \& Gallego. 2006, "From 'New".
} 
para enfrentar el problema y cuando las circunstancias políticas son propicias para emprender el cambio ${ }^{11}$.

El reconocimiento del problema hace referencia a que actores sociopolíticos, como actores que forman parte de la institucionalidad del Estado, de los poderes ejecutivos y/o legislativo, o de instancias informales - de la sociedad civil- en las que logran visibilizar situaciones que ven como afectaciones al bienestar social y/o ciudadano, capturar la atención de otros actores y a partir de ello promueven intervenciones sobre los problemas expuestos. Las alternativas para enfrentar estos problemas son elaboraciones tecnocráticas en las que participan expertos de los poderes públicos y/o de organismos de la sociedad civil. La idea de circunstancias políticas propicias hace referencia a que la propuesta sea susceptible de obtener respaldos de poder, lo que puede implicar la necesidad de alcanzar apoyos al interior del gobierno, lograr la voluntad presidencial favorable, cuando la decisión debe darse al interior del poder ejecutivo; obtener apoyos en el Congreso, en el caso de una propuesta de ley; o una opinión ciudadana favorable, que podrá ser clave a la hora de las decisiones que deban tomarse en los poderes ejecutivo y/o legislativo.

La convergencia de estas tres corrientes -problemas, soluciones y política- es lo que Kingdon ha denominado la ventana de oportunidad, que permite que el tema en discusión avance en las prioridades de los poderes públicos y, finalmente, pase a la etapa de decisión, aunque alcanzar esta etapa no asegura que la decisión sea favorable ${ }^{12}$.

Un aspecto complementario del enfoque de las corrientes múltiples es cómo se instalan los temas en la agenda pública y/o cómo se seleccionan los problemas que luego serán abordados por los actores formales del sistema político. Sobre ello, Cobb, Ross y Ross ${ }^{13}$ exponen tres modelos de construcción de la agenda. En el modelo de iniciativa externa, grupos que se ubican fuera de la estructura del Estado articulan quejas, tratan de involucrar a otros grupos ciudadanos para crear presión sobre los poderes públicos, para que estos los incluyan en la agenda formal y les den seria consideración. En el modelo de movilización, líderes políticos plantean temas y acuden al apoyo ciudadano para su validación popular. Puede darse a través del anuncio de un nuevo programa, que es el resultado de un proceso de decisión de actores formales del Estado, pero el asunto es como este logra que los ciudadanos demanden el bien o servicio que provee ese programa; es decir, cómo el tema pasa de la agenda formal a la agenda pública. En el modelo de iniciativa interna las propuestas surgen al interior de los poderes públicos o en ámbitos muy cercanos y conectados con ellos, a partir de lo cual los promotores buscan vincular a grupos de interés para crear presión sobre los decisores, pero sin desarrollar

\footnotetext{
${ }^{11}$ Kingdon, John. 2011. Agendas, Alternatives, and Public Policies, Glenview, Illinois, Longman-Pearson.

12 Kingdon. 2011, Agendas, Alternatives.

${ }^{13}$ Cobb, Roger, Ross, Jennie-Keith \& Ross, Marc. 1976. "Agenda Building as Comparative Political Process", in The American Political Science Review, vol. 70, № 1, Cambridge, pp. 126-138.
} 
esfuerzos por vincular a amplios segmentos ciudadanos ni por establecer el tema en la agenda pública ${ }^{14}$.

El institucionalismo histórico es una aproximación convergente con el procesalismo institucional. Skocpol señala que "el institucionalismo histórico centrado en lo político busca responder preguntas sobre qué pasó, cuándo y cómo, y por qué algunas políticas públicas que pudieron haber surgido no lo hicieron" ${ }^{15}$. Steinmo agrega que "los estudiosos del Institucionalismo Histórico buscan desentrañar por qué se tomaron ciertas decisiones y se obtuvieron determinados resultados"16.

Así, mientras el Procesalismo Institucional se enfoca en la convergencia de corrientes que concurren al surgimiento o cambio de una política pública, el institucionalismo histórico ve a esa convergencia como un proceso histórico en el que las decisiones que van surgiendo van dando forma a las instituciones y las políticas públicas, lo que a su vez, configura las actuaciones concretas de ellas y los alcances de las políticas públicas ${ }^{17}$.

Para ambas perspectivas la historia importa. Para el Institucionalismo Histórico las instituciones, y por extensión las políticas públicas, son construidas y reconstruidas a lo largo del tiempo ${ }^{18}$, cuestión que es recogida a través de estudios con perspectiva histórica. Woolcock, Szreter y Rao agregan que el estudio de la historia aporta información para identificar mecanismos específicos de influencia, apreciar la importancia del contexto y lograr una mejor comprensión de los procesos, de las contingencias específicas, de las dinámicas que ocurren y de las coaliciones que surgen entre cambiantes conjuntos de actores ${ }^{19}$. De este modo, el Institucionalismo Histórico pone atención "al desarrollo tanto de procesos causales como de resultados políticos importantes en períodos de tiempo prolongados" ${ }^{20}$. Para el Procesalismo Institucional la historia también importa en tanto "su forma de conocimiento preferido es un

\footnotetext{
${ }^{14}$ Además, Cobb, Ross \& Ross. 1976, “Agenda Building”, p.126, distinguen dos tipos de agenda: la agenda pública que incluye "un conjunto de temas que han adquirido alto nivel de visibilidad e interés público", y la agenda formal que "es el listado de temas a los cuales los decisores han formalmente aceptado darles seria consideración".

${ }^{15}$ Skocpol, Theda. 1995. "Why I am and Historical Institutionalist", in Polity, vol. 28, N 1 , Chicago, 1995, pp. 103106.

${ }^{16}$ Steinmo. 2008, "What is", p. 163.

17 Trigo, Luis. 2016. "Una revisión de los aportes del Institucionalismo Histórico a la Ciencia Política”, en Revista Colombiana de Ciencias Sociales, vol. 7, № 1, Medellín, pp. 224 - 241; Pierson, Paul. 1996. "The path to European integration. A historical institutionalist analysis", in Comparative Political Studies, vol. 29, № 2, Newbury Park, pp. 123-163.

18 Pierson, Paul y Skocpol, Theda. 2008. "El institucionalismo histórico en la ciencia política contemporánea", en Revista Uruguaya de Ciencia Política, vol. 17, № 1, Montevideo, pp. 7 - 38; Thelen, Kathleen. 1999. "Historical Institutionalism in Comparative Politics", in Annual Review of Political Science, vol.2, Palo Alto, pp. 369 - 404.

${ }_{19}$ Woolcock, Michael, Szreter, Simon \& Rao, Vijayendra. 2010. How and Why Does History Matter for Development Policy?, Policy Research Working Paper №542, Development Research Group, Poverty and Inequality Team, Washington DC, The World Bank.

20 Pierson y Skocpol. 2008, "El institucionalismo", p. 16.
} 
conjunto consistente e interesante de generalizaciones analíticas fundamentadas históricamente" ${ }^{21}$.

Peters, Pierre y King son escépticos en que el Institucionalismo Histórico pueda dar una explicación causal de por qué ocurren cambios institucionales y de política pública, dada su persistencia en focalizarse en cambios que serían dependientes de una trayectoria originada en una coyuntura crítica ocurrida en el pasado y donde los cambios significativos serían la consecuencia de un desequilibrio en esa trayectoria ${ }^{22}$. Consecuentemente, las versiones más recientes de los trabajos del Institucionalismo Histórico habrían dado paso a narrativas que dan cuenta de "un curso de evolución, en vez de una persistencia del patrón inicial" 23. Dado ello, el Procesalismo Institucional aparece como el complemento adecuado para aportar elementos que permitan arribar a explicaciones causales en el análisis del proceso de formulación de políticas públicas.

El Institucionalismo Histórico ocupa el método narrativo para exponer la secuencia de hechos que configuraron el cambio institucional y de política pública, y, con ello, aportar a la comprensión acerca de cómo se conformaron y reformaron las instituciones y las políticas públicas. El Procesalismo Institucional aporta modelos analíticos acerca del proceso de formulación de políticas públicas que permiten desarrollar afinadas explicaciones causales del cambio institucional y de políticas públicas ${ }^{24}$. De este modo, la convergencia entre Institucionalismo Histórico y el Procesalismo Institucional permite recoger tanto la evolución de procesos históricos, como desentrañar los alcances de los sucesos que se desatan en los esfuerzos de cambio del estado vigente de la política pública.

Esta convergencia resulta necesaria, entonces, para poder comprender tanto la evolución de largo plazo, como el conjunto de coyunturas específicas que fueron dando forma y contenido al sistema previsional chileno.

\section{Trayectoria de la Previsión Chilena}

\section{Iniciativas Tempranas}

Durante el siglo XIX e inicios del XX el desarrollo de esquemas jubilatorios se centró en el personal que cumplía funciones relacionadas al poder ejecutivo. Tres tipos de personal destacan en estos desarrollos: de la administración pública, del ámbito militar y de los ferrocarriles del Estado.

\footnotetext{
21 Barzelay \& Gallego. 2006, "From 'New”, p. 538.

22 Peters. B. Guy, Pierre, Jon \& King, Desmond S. 2005. "The Politics of Path Dependency: Political Conflict in Historical Institutionalism", in The Journal of Politics, vol. 67, no 4, Chicago, pp. 1275-1300.

23 Peters, B. Guy. 2019. Institutional Theory in Political Science, Northampton, Massachusetts, Edward Elgar, p. 84.

24 Barzelay \& Gallego. 2006, "From 'New".
} 


\section{Jubilaciones en la Administración Civil}

En los primeros años de la república se mantuvo la práctica de jubilaciones del servicio civil que venían desde la época colonial. Estas no se otorgaban debido al reconocimiento de un derecho que podía ser impetrado por cualquier persona que cumpliera los requisitos, sino que se concedía en una revisión caso a caso, como una cuestión excepcional, que debía ser aprobada en el Parlamento ${ }^{25}$. Aún con la discrecionalidad que ello implicaba, el criterio básico que se tenía para concederlas era el de los años de servicio del peticionario, debiendo haber cumplido un mínimo de 10 años de trabajo. Para O'Higgins, sin embargo, las jubilaciones debían seguir al ideal meritocrático que buscaba establecer en la Administración Pública. Señalaba que "los empleos deben darse, no al que más ha hecho, sino al que mejor puede desempeñarlos. Los retiros con sueldo, las jubilaciones son premio a los primeros, y esto lo resarcen los segundos con el cumplimiento de sus deberes" 26 .

Dado ello, en 1820, una solicitud de jubilación levantó una discusión en el Senado acerca de la conveniencia de mantener este criterio, de lo cual surgió una propuesta al Director Supremo para que estas se otorgaran conforme a la ineptitud física o moral que el solicitante hubiera contraído en el ejercicio de la función pública, la que debía ser demostrada en audiencia fiscal y, de concederse, la jubilación debía ser equivalente a "la mitad del sueldo del último empleo que servía, i jamás con otro aumento" ${ }^{27}$. Consecuentemente, O’Higgins asentó el principio que ningún empleado que tuviese la capacidad de desempeñarse en su trabajo podía jubilar y que solo una "inhabilidad física o moral" que le impidiese ejercer sus funciones era causa de jubilación, la que debía corresponder a la mitad del último sueldo ${ }^{28}$.

Siguiendo este principio, el decreto de reforma de empleados civiles, del 12 de noviembre de 1827, mantuvo el retiro por imposibilidad física y estableció, adicionalmente, un retiro con montos diferenciados según años de servicio para aquellos que "queden fuera del servicio", y respetó las condiciones de quienes se hubieren retirado o jubilado con anterioridad a la fecha de dictación de ese decreto ${ }^{29}$. Luego, el 12 de enero de 1829, el gobierno presidido por Francisco Antonio Pinto presentó al Congreso un proyecto de reforma a la jubilación de los empleados públicos, que reconocía a los empleados públicos el tiempo servido durante la

\footnotetext{
25 López, Elvira. 2014. El proceso de construcción estatal en Chile. Hacienda pública y burocracia (1817-1860), Santiago, Centro de Investigación Diego Barros Arana/DIBAM.

${ }^{26}$ Urzúa, Germán y García, Ana María. 1971. Diagnóstico de la Burocracia Chilena (1818-1969), Santiago, Editorial Juridical de Chile, p. 21.

${ }^{27}$ Diario de Sesiones del Senado [en adelante DSS], Sesión 298 Ordinaria, 20 de noviembre de 1820, p. 503.

28 Urzúa y García, op. cit., p. 22.

${ }^{29}$ Comisión Nacional, Sesión 34, 12 de noviembre de 1827, p. 151. El mismo decreto establece que los montos de retiro irían de: " 5 a 15 años [de servicio], la cuarta parte del sueldo que disfruta; de 15 a 25, la mitad; de 25 a 35, las tres cuartas partes; de 40 arriba, el todo".
} 
dominación española, el que fue rápidamente aprobado el 30 de ese mes en los mismos términos planteados por el gobierno ${ }^{30}$.

Luego de la reforma al Servicio Civil, a instancias de una iniciativa del gobierno de José Joaquín Prieto, comenzó a discutirse una ley propiamente de jubilaciones de los empleados públicos, la que fue finalmente aprobada el 19 de octubre de 1832. Los artículos 10 y 3 으 exponían el corazón de la ley en los siguientes términos:

"Artículo $1^{\circ}$. Los empleados civiles que habiendo desempeñado bien i cumplidamente las obligaciones de sus destinos se imposibilitaren para continuar en el servicio, obtendrán la jubilación con arreglo a la escala siguiente: los que hubieren llenado 5 a 15 años gozarán la cuarta parte del sueldo señalado al empleo efectivo que sirvieren al tiempo de jubilárseles; de 15 a 25 la mitad; de 25 a 40 las tres cuartas partes; de cuarenta para arriba, todo.

Art. $3^{\circ}$. Los empleados que hubieren cumplido cuarenta años de servicios i sesenta i cinco de edad, podrán obtener su jubilación, aun cuando no justificaren su absoluta inhabilidad para continuar, siempre que el Gobierno hallare que necesitan de descanso." ${ }^{31}$

Veinticuatro años más tarde, el presidente Manuel Montt presentó un proyecto de reforma, argumentando que la ley "no guarda la justa proporción que ha de haber entre el sueldo i el servicio prestado" 32 . La propuesta presidencial fue aprobada por el Congreso y comenzó a regir el 20 de agosto de 1857. Esta Ley concedía derecho a jubilación a los empleados públicos y de los establecimientos educacionales del Estado o financiados por éste, que devinieren en imposibilidad física o moral absoluta para ejercer sus funciones, siempre que hubieren acumulado al menos 40 años de servicio y más de 65 años. La jubilación correspondía a "una cuarentava parte de su renta por cada uno de los años de servicio que hubiere prestado" 33 .

El tema jubilatorio volvió a la agenda de gobierno en la década de 1890, dadas las distintas bases de cálculo que se habían estado aplicando desde la vigencia de la ley de 1.857. En 1883 se había establecido una regla que señalaba que las jubilaciones alcanzarían una proporción del $75 \%$ del sueldo en los casos en que hubieren recibido aumentos de remuneraciones o se les hubiere asignado sueldo desde esa fecha ${ }^{34}$. La regla también consideraba que los empleos que hubieren sido creados con anterioridad a 1880 y que no hubieren recibido aumentos de sueldo con posterioridad a ese año, debían jubilarse en base al sueldo completo. Pero la Comisión de Reorganización de la Administración Pública, creada por ley, en octubre de $1892^{35}$, constató

\footnotetext{
30 DSS, Sesión 88, 30 de enero de 1829, pp. 73.

${ }^{31}$ Flores, Eliodoro. 1919. Jubilación del Profesorado, Santiago, Imprenta Universitaria, p. 19.

32 Diario Sesiones de la Cámara de Diputados [en adelante DSCD], Sesión 6 Ordinaria, 19 de junio de 1856, p. 28.

33 Flores. 1919, Jubilación del, p. 21.

${ }^{34}$ DSCD, Sesión 11 Ordinaria, 1 de julio de 1893, p. 137.

35 La Comisión de la Reorganización de la Administración Pública fue creada por una ley aprobada en el Congreso el 29 de octubre de 1892 y tuvo el propósito de proponer reformas a los montos de los sueldos y pensiones de los empleados públicos. Ver: DSCD, Sesión 7 Extraordinaria, 29 de octubre de 1892, pp. 68-69.
} 
que en reiterados casos la regla no se cumplía y que había inadvertencia acerca de estas precisiones o confusión en su aplicación ${ }^{36}$.

La Comisión entregó su informe y proyecto de reforma a las jubilaciones en Julio de 1893, pero el Congreso comenzó a discutirlo en septiembre de 1898. La discusión en el Congreso consideró que eran muy pocos los empleados que se podían acoger a la Ley de 1.857 y que "permitirles que se retiren con el sueldo íntegro a los empleados que hayan servido durante cuarenta años, es acordarles un premio bien merecido" ${ }^{37}$. La Ley №1.146 fue promulgada el 28 de diciembre de 1898, con el siguiente artículo único:

"Los empleados públicos que justificaren haber servido cuarenta años, sin tomar en cuenta abonos, i que hubieran cumplido sesenta i cinco de edad, podrán jubilarse con una pensión anual igual al sueldo íntegro asignado a sus respectivos empleos, sin necesidad de justificar imposibilidad física o moral" 38 .

\section{Jubilaciones Militares}

Aparte de las jubilaciones al personal de la administración civil del Estado, en el periodo previo a 1924 también se constatan normativas jubilatorias para militares. Entre estas iniciativas es dable mencionar que entre las primeras estuvieron vinculadas a jubilaciones para quienes participaron en conflictos bélicos, destacando un decreto de 1817 que entregaba montepíos a las madres o esposas de los fallecidos durante la independencia y otro de 1819 que entregaba jubilaciones a quienes resultaron inválidos ${ }^{39}$. En 1819 el gobierno de O'Higgins creó el Cuerpo de Inválidos de Santiago (también Ilamado Cuerpo de Aguerridos), con el propósito de "asistir a las necesidades de los inválidos de la campaña por la independencia" 40 .

Otras iniciativas de entrega de pensiones a inválidos del ejército y armada se establecieron luego para quienes no pudieran seguir en servicio activo $y$, también, a viudas y madres de fallecidos en conflictos bélicos ${ }^{41}$. Entre ellas destacan la Lei de Retiro para el Ejército y la Armada de 1839, que establecía que los oficiales tendrían una jubilación en relación con sus años de servicios, tendiendo la posibilidad de retiro con su sueldo completo ${ }^{42}$; y la Ley de Montepío

\footnotetext{
${ }^{36}$ DSCD, Sesión 11 Ordinaria, 1 de julio de 1893, p. 137.

37 DSCD, Sesión 9, 11 de noviembre de 1898, pp. 129-130.

${ }^{38}$ República de Chile, Ley $N^{\circ} 1.146,28$ de diciembre de 1898. Recuperado de: http://bcn.cl/2ozv9 (Consultado el 30 de abril de 2021].

39 Dinator, Raúl. 2013. "La Previsión Militar desde el inicio de la emancipación hasta la creación de la Caja de Previsión de la Defensa Nacional", en Anuario de la Academia de Historia Militar, no 27, Santiago, pp. 48-79.

40 Ejército de Chile, Creación del Cuerpo de Inválidos de Santiago, 2020. Recuperado de: https://www.ejercito.cl/efemerides/efemerides/MTUz (Consultado el 30 de noviembre de 2020).

41 Un relato de la evolución de las leyes y decretos de iniciativas de pensiones parar el mundo militar ver: Dinator. 2013, “La previsión", pp. 44 - 75.

42 Dinator. 2013, “La previsión”, pp. 52 - 53.
} 
Militar, del 6 de agosto de 1855, que se definía como "una institución piadosa para la familia de los [...] oficiales del Ejército y la Armada" ${ }^{43}$

A partir de la Guerra del Pacífico, el gobierno impulsó leyes que entregaban pensiones o montepíos a familiares de los combatientes. Entre ellas estaban la ley del 12 de septiembre de 1879 que otorgó una pensión a la viuda de Arturo Prat y que fue incrementada por Ley del 1 de septiembre de 1880; o la Ley del 18 de junio de 1880, que concedía pensión a los padres de aprendices mecánicos que fallecieron en el Combate Naval de lquique sin dejar viudas o hijos; o la que concedió pensión a la viuda e hija soltera del exministro de Guerra y Marina Rafael Sotomayor. Todas ellas fueron acciones específicas, por lo que la Ley de Recompensas Militares, del 22 de diciembre de 1881, vino a establecer una norma general para regular el otorgamiento de pensiones para oficiales y tropa del Ejercito, la Armada y la Guardia Nacional de Santiago y Valparaíso que, por acción de servicios durante la campaña de Perú y Bolivia, hubiesen quedado inutilizados para la guerra, y para las familias de aquellos "que hubieren muerto en la referida campaña o como consecuencia de ella" ${ }^{44}$.

Aunque los boletines de las sesiones de la Cámara de Diputados la señalan como iniciativa del Diputado por Vallenar Eulogio Allendes, las disposiciones de la Constitución de 1833 le otorgaban al presidente de la República iniciativa de gasto. Así, la participación del ministro de Hacienda, Luis Aldunate, fue clave para acotar el beneficio a la gravedad de las heridas recibidas para determinar el tipo de inhabilidad a la que sería adscrito el beneficiario, desechándose la categorización según el nivel jerárquico del peticionario ${ }^{45}$. En el debate se expusieron cuestiones militares, de la necesidad de recompensar a los combatientes, fisiológicas, como los referidos al grado de invalidez por las heridas de guerra, y económicas, referidas a la capacidad del Estado para hacer frente a los gastos que la propuesta de ley demandaría ${ }^{46}$. El debate también estuvo muy influido por el estado de la opinión pública y crónicas de prensa, que eran favorables a concederles pensiones a los militares y que mostraban el deterioro económico de ellos al regreso desde el frente de combate y de las familias de los fallecidos en la guerra ${ }^{47}$.

\footnotetext{
${ }^{43}$ República de Chile. 1855. Lei de Montepío Militar, Santiago, Imprenta Nacional, p. 3.

${ }^{44}$ Méndez, Carlos. 2009. Héroes del silencio. Los veteranos de la Guerra del Pacífico, Santiago, Centro de Estudios Bicentenarios, p. 111.

45 DSCD, Sesión 6 Ordinaria, 21 de junio de 1881, p. 53.

46 Una revisión del debate público y político respecto a la recompensa que debían recibir los combatientes de la Guerra se puede encontrar en: Méndez. 2009, Héroes del, pp. 55 - 74.

47 Las expresiones de descontento con la situación aflictiva de los ex combatientes y sus familias, por la escasa ayuda provista por el Estado, continuaron después de la promulgación de la ley, pues ésta no incluyó cláusulas de reajustabilidad y porque se consideraba que los procedimientos para obtener el beneficio eran intrincados, se debían hacer en Santiago y poca información estaba disponible, al punto que un número significativo de solicitudes se hicieron por las familias al fallecimiento del titular del derecho. Una caricatura reportada por Méndez. 2009, Héroes del, p. 69, de la Colección Academia de Historia Militar, del 7 de octubre de 1905, expone un diálogo entre un veterano de la guerra y un empleado de una casa de empeño, donde el veterano exclama: "Donde usted las vé, estas
} 
El gobierno de José Manuel Balmaceda, en 1887 y 1888 estableció nuevas normativas relacionadas a las pensiones de combatientes en conflictos bélicos. Luego, en la administración de Jorge Montt, se establecieron similares normas para aquellos involucrados en la Guerra Civil de $1891^{48}$.

Dos décadas más tarde, hacia el término de su mandato, el presidente Ramón Barros Luco presentó un proyecto de creación de una Caja de Pensiones para el personal del Ejército, teniendo como propuesta novedosa que los mismos afiliados aportaran parte de su sueldo para el financiamiento de los beneficios. El ministro de Guerra, Ramón Corbalán, al presentar el proyecto en el Congreso planteó que esta iniciativa "en vez de importar gastos, significa una economía"49. El diputado Alejandro Huneeus presentó un contraproyecto para una "Caja de Retiro i Montepío" para el personal del ejército y armada en diciembre de $1914^{50}$, siendo finalmente esta última propuesta la discutida por el Congreso y que terminó siendo la Ley №3.029 del 9 de septiembre de 1915 que creó para el personal del ejército y de la armada una Caja de Retiro y Montepío. Se estableció que los dineros de esta institución se guardarían en la Caja Nacional de Ahorros, que los mismos afiliados debían aportar parte de su salario, que la pensión de retiro estaría en relación con los años de servicio y que a los 35 años de servicio sería con sueldo íntegro ${ }^{51}$.

\section{Jubilaciones de Ferroviarios}

Las jubilaciones de empleados ferroviarios es otro hito en el sistema previsional chileno. El gobierno del presidente Pedro Montt emprendió la reorganización de Ferrocarriles del Estado, la que fue aprobada por el Congreso mediante Ley №1.933, del 8 de febrero de $1907^{52}$. Dos años más tarde, al término de la autorización otorgada por el Congreso, el presidente informaba acerca del proyecto que materializaba la reorganización, en el que se incluía la creación de la Caja de Ahorros para los empleados de la Empresa de Ferrocarriles del Estado. Ello se materializó mediante Ley №2.498, del 1 de febrero de 1911, ya en el mandato del presidente Ramón Barros Luco.

La Caja de Ahorros se constituyó como un fondo de retiro para el personal ferroviario de planta y contrata. El diseño de esta Caja requirió gran apoyo técnico, en lo que destacaron Eugenio Frías Collao, jefe de la Oficina del Trabajo; José Antonio Carvajal, secretario de la

\footnotetext{
medallas nos las dio la Nación en cambio de haberle dado nosotros mil millones en salitre, y hoy tenemos que empeñarlas para no morir de hambre".

48 Ver Dinator. 2013, "La previsión", pp. 61-64.

${ }^{49}$ DSCD, Sesión 58 Ordinaria, 24 de agosto de 1914, p. 1624.

50 DSCD, Sesión 50 Extraordinaria, 16 de diciembre de 1914, p. 1156.

${ }^{51}$ República de Chile, Ley 3.029, 9 de septiembre de 1915. Recuperado de: http://bcn.cl/2p06l (Consultado el 30 de abril de 2021).

52 Zelada, Marco Aurelio. 1936. Aporte al conocimiento de la legislación social ferroviaria: Génesis de la Caja de Retiros y de Previsión Social de los Ferrocarriles del Estado, Santiago, Talleres Gráficos San Vicente, p. 1.
} 
Dirección General de la Empresa de Ferrocarriles del Estado, Luis Carvajal; Omer Huet, Ingeniero Belga que, como director general, llevó a cabo la reorganización de la Empresa, y Juan Manuel Valle, sucesor de Huet en el cargo ${ }^{53}$. Frías tuvo una participación muy activa e influyente en la redacción de la Ley №2.498, que recogía el capítulo del informe de reorganización de la Empresa, que proponía la creación de la Caja de Ahorros. Luego, junto a Carvajal y Carvajal trabajaron en la redacción de los reglamentos de funcionamiento de la Caja y de adquisición de propiedades, lo que se concretó en los Decretos Supremo №619, del 10 de marzo de 1911, y №2.221, del 27 de Julio de 1911. Huet fue el primero en proponer la Caja, como mecanismo de apoyo social a los trabajadores, y luego apoyó su concreción, labor que fue continuada por Valle. Aunque el proyecto de Caja de Ahorros redactado por Frías incluía a todo el personal ferroviario, en el trámite parlamentario fueron excluidos de ella los obreros a jornal, por la amenaza de huelga que hicieron si se les incluía en la ley ${ }^{54}$, dado que ello implicaba un descuento de su remuneración y, en consecuencia, un menor ingreso efectivo mensual.

La Caja fue reformada mediante Ley №3.379, del 10 de mayo de 1918, pasando a denominarse "Caja de Retiros i de Previsión Social de los Ferrocarriles de Estado". Con ello, al fondo de retiro se le sumaban actuaciones en ámbitos de asistencia, protección, bienestar y culturales y beneficios de pensión de jubilación. Asimismo, la Caja reformada cubriría a un mayor número de empleados y obreros de la empresa.

La reforma de la Caja de Ahorros demandó un fuerte trabajo técnico y político. Ámbitos del poder ejecutivo habían quedado disconformes con la exclusión de los jornaleros en la ley de 1911, por lo que a poco andar surgieron ideas para reformarla. Zelada relata que ya había conversaciones en esa dirección en 1914 y que en 1916 estas pasaron a la etapa de desarrollar estudios con ese propósito. Nuevamente el jefe de la Oficina del Trabajo, Eugenio Frías Collao, tomó un rol protagónico en ello, al que luego se le unió Julio Molina Núñez, abogado, oficial primero del Ministerio de Industrias y Obras Públicas, y luego Juan Santa Cruz Anguita, funcionario también del mismo ministerio, quien estuvo a cargo de los cálculos actuariales y financieros del proyecto de reforma. El proyecto de ley fue enviado a trámite legislativo por el presidente Juan Luis Sanfuentes, en Julio de 1916, y suscrito también por el ministro de Industrias y Obras Públicas, Ángel Guarello, dado que la Empresa de Ferrocarriles del Estado dependía de ese Ministerio ${ }^{55}$.

En la Cámara de Diputados el proyecto sufrió severas alteraciones, que en opinión del gobierno lo desnaturalizaban. Luis Claro Solar, Senador y ministro de Hacienda entre abril y septiembre de 1918, asesorado por Eugenio Frías Collao, intervino para rechazar las modificaciones más significativas, mantener lo sustancial de la iniciativa enviada por el

\footnotetext{
53 Zelada. 1936, Aporte al, p. 3.

54 Un relato de todo este proceso en: Zelada. 1936, Aporte al, pp. 2-4.

55 Un relato de este proceso en: Zelada. 1936, Aporte al, pp. 4 - 6.
} 
presidente Sanfuentes y acoger la propuesta del Diputado Malaquías Concha, que ampliaba el sistema de jubilación del personal ferroviario ${ }^{56}$.

El empleo público fue cobrando relevancia a lo largo del siglo XIX. Barría anota que entre 1860 y 1919 los funcionarios civiles pasaron de 2.293 a 26.216 y que los militares se incrementaron desde 3.751 en 1860 a 22.585 en $1900^{57}$. Las disposiciones sobre jubilaciones, las reformas administrativas de la década de 1880 y el establecimiento de requisitos meritocráticos para el desempeño de un empleo público ${ }^{58}$ fueron una lógica consecuencia de la expansión señalada y de los debates sobre el desempeño de la administración pública y las compensaciones a empleados civiles y militares. Asimismo, los trabajadores de ferrocarriles mostraron capacidad de organización y negociación para lograr beneficios laborales ${ }^{59}$, en una empresa con importancia estratégica en la época.

Durante el periodo, las jubilaciones se establecieron para el personal de órganos del Estado, que en el inicio se daban en una revisión caso a caso, donde el criterio central era la invalidez física o moral del peticionario para seguir prestando servicios. En el desarrollo de los esquemas jubilatorios durante el siglo XIX y principios del XX, un tema que siempre estuvo presente en las decisiones fue, por un lado, si ello generaba un incentivo para retirarse de la Administración Pública; y, por otro, el efecto que tendría el otorgamiento de las pensiones sobre las finanzas públicas. En el periodo siguiente se generaría un intenso movimiento por establecer derechos jubilatorios que se expandieran más allá del empleo público y que fuera exigible por cualquier persona que cumpliera los requisitos.

\section{El surgimiento de las Cajas de Previsión}

La expansión del debate por la cuestión social, hacia fines del siglo XIX y principios del XX, junto al surgimiento de mecanismos de autoayuda de los trabajadores, como las Mutuales, Sociedades de Socorros Mutuos y Mancomunales, abrió la discusión sobre la necesidad de establecer mecanismos previsionales hacia segmentos de trabajadores distintos a los empleados públicos. Hasta 1924 estas organizaciones eran "el único tipo de previsión al que podrían aspirar aquellos sectores de trabajadores que poseían una mayor capacidad de organización y de ahorro" ${ }^{60}$.

\footnotetext{
56 DSS, Sesión 68 Extraordinaria, 1 de mayo de 1918, pp. 1344 - 1347.

${ }^{57}$ Barría, Diego. 2015. "Empleados públicos y clase media, Chile 1880 - 1920: un análisis exploratorio a partir de cifras oficiales”, en Revista de Historia y Geografía, №32, Santiago, pp. 77 - 100.

${ }^{58}$ Barría, Diego. 2009. "En busca del mérito: la discusión académica en torno a los empleados públicos en Chile, 18841920", en Estudios Ibero-Americanos, vol.35, N22, Logroño, pp. 148 - 165.

${ }^{59}$ Vergara, Felipe. 2021. "La organización obrera ferroviaria. Antecedentes, procesos y logros tras el desarrollo de las huelgas 1906-1923”, en Revista Notas Históricas y Geográficas, №24, Valparaíso, pp. 273 - 319.

${ }^{60} \mathrm{Grez}$, Sergio. 1994. "La trayectoria del mutualismo en Chile (1853-1990). Apuntes para su estudio", en Mapocho, $N^{\circ} 35$, Santiago, p.301.
} 
El debate por la protección hacia los trabajadores fue recogido en tesis de la Facultad de Derecho de la Universidad de Chile ${ }^{61}$. A su vez, Valentín Letelier, en la Convención Radical de 1906 , aludió a la necesidad de crear cajas de previsión para los trabajadores ${ }^{62}$. El movimiento obrero también planteó la idea, aunque esporádicamente y no de manera principal ${ }^{63}$. A su vez, la Oficina del Trabajo propuso crear cajas previsionales desde, al menos, fines de la década de $1900^{64}$, lo que implica que el desarrollo de la intervención estatal en la sociedad fue posible no solo por las denuncias y movilización social, sino que el desarrollo y acción de la burocracia estatal también jugó un papel fundamental en el desarrollo de la previsión social en las primeras décadas del siglo $X X X^{65}$. Sin embargo, solo con la llegada de Arturo Alessandri al gobierno se pudo avanzar en protección previsional para amplios espectros de trabajadores. Hacia el fin de ese gobierno surgen las tres principales Cajas, las que a fines de la década de 1970 congregaban al $94,09 \%$ de los afiliados al sistema previsional ${ }^{66}$.

El surgimiento de la Caja del Seguro Obligatorio marco el inicio de la declinación del mutualismo como forma de previsión de los trabajadores, dada la pesada carga que significaba cotizar al organismo mutual y a la Caja, cuestión que se profundizó notoriamente con la reforma de 1952, que estableció la cotización obligatoria al Seguro Obrero ${ }^{67}$.

\section{La Caja del Seguro Obligatorio}

Arturo Alessandri asumió la Presidencia de la República el 23 de diciembre de 1920. Ya en su precandidatura por la Alianza Liberal había señalado la necesidad de avanzar en un sistema de protección para los trabajadores $y$, en particular, para el momento del retiro de la fuerza laboral, argumentando que "la sociedad no puede ni debe abandonar a la miseria y al infortunio a quienes entregaron los esfuerzos de su vida entera a su servicio y progreso" ${ }^{68}$. Esta visión se plasmó en su programa de gobierno, que expresaba el propósito de:

\footnotetext{
${ }^{61}$ Morris, James. 1967. Las elites, los intelectuales y el consenso: estudio de la cuestión social y del sistema de las relaciones industrials en Chile, Santiago, Editorial del Pacífico, pp. 79 - 81; Grez, Sergio. 1995. La "cuestión social" en Chile. Ideas y debates precursores (1804-1902), Santiago, DIBAM, pp. 99 - 100.

62 Hinojosa, Francisco. 1967. El libro de Oro de los Empleados Particulares, Santiago, Editorial Nascimento, pp. 35-36; Hinojosa, Francisco. 1967. La Caja de Previsión de Empleados Particulares. Génesis: cómo, cuándo y dónde surgió la iniciativa de su creación, Santiago, sin sello editorial, pp. 9 - 10.

63 Esto se puede observar en: Grez, Sergio. 2001. "El escarpado camino hacia la legislación social: debates, contradicciones y encrucijadas en el movimiento obrero y popular (Chile: 1901-1924)", en Cuadernos de Historia, $\mathrm{n}^{\circ}$ 21, Santiago, pp. 119 - 182.

${ }^{64}$ Ahumada, Daniel y Salas, Alejandro. 2018. "La participación de la Oficina del Trabajo en la configuración del sistema de previsión social chileno, 1909-1925”, en Revista de Historia y Geografía, N³9, Santiago, pp. 73 - 97.

65 Yáñez, Juan Carlos. 2008. La intervención social en Chile, 1907-1932, Santiago, Ril Editores.

${ }^{66}$ Cheyre, Hernán. 1988. "La Previsión en Chile Ayer y Hoy: Impacto de una Reforma", Santiago, Centro de Estudios Públicos.

67 Venegas y Grez. 2021, "Historiografía del”; Grez. 1994, "La trayectoria”.

68 "El discurso-programa de don Arturo Alessandri", El Mercurio, Santiago, 29 de abril de 1920, p. 15.
} 
“... establecer una legislación social sobre la base de la solidaridad humana y de la justicia social para producir la armonía entre el capital y el trabajo; [atender] las principales necesidades del proletariado, tales como ... el otorgamiento de los medios para satisfacer sus necesidades físicas y morales, protección en los accidentes, en las enfermedades y en la vejez; [dar] amparo en el trabajo a las mujeres y a los niños; [a la vez que expresaba] la necesidad y resolución inquebrantable de resolver el problema social que era en aquellos momentos palpitante y urgente" ${ }^{\prime 69}$.

A poco de asumir, Alessandri nombró a Moisés Poblete Troncoso como Director de la Oficina del Trabajo y le asignó la tarea de redactar un proyecto de Código del Trabajo. El motivo para convocar a Poblete, Alessandri lo exponía de la siguiente manera:

"Lo llamé entonces a Ud. cuyos vastísimos y excepcionales conocimientos en los problemas sociales y sobre legislación obrera yo conocía desde antiguo. Le pedí que, en el más breve plazo posible, me redactara un cuerpo orgánico de disposiciones y leyes sociales en donde se resolvieran prácticamente todos los problemas más entregados a la consideración del mundo por el Tratado de Versalles"70.

El proyecto de Ley sobre Código del Trabajo fue presentado por el gobierno de Alessandri a tramitación en el Congreso el 4 de junio de 1921 y en él se incluía, como Libro IV ${ }^{71}$, la creación de la Caja Nacional de Seguro Obrero Obligatorio ${ }^{72}$. La creación de la Caja se fundamentaba en tres ideas principales: (i) la necesidad de proteger a los obreros ante los riesgos de accidentes y enfermedades del trabajo industrial; (ii) alivianar la carga financiera de la Beneficencia Pública, dado que sería la Caja la que costearía las atenciones de salud de sus afiliados; (iii) la necesidad de establecer sistemas de información estadísticos para reducir la siniestralidad y planificar racionalmente los esquemas de seguros ${ }^{73}$. Aun así, el Libro IV no fue discutido en el Congreso.

Al año siguiente, el diputado y presidente de la Asociación Médica de Santiago, Exequiel González Cortés, presentó un nuevo proyecto sobre previsión social, que contemplaba jubilaciones, seguros y asistencia médica. González fundamentó su propuesta ${ }^{74}$ en: (i) la

\footnotetext{
${ }^{69}$ Arturo Alessandri. 1967. Recuerdos de Gobierno. Tomo I, Santiago, Editorial Nascimento, p. 33.

70 Poblete. 1949. El derecho, p. 20.

${ }^{71}$ El Libro I del proyecto trataba sobre los contratos de trabajo, el Libro II sobre la creación de sindicatos y el Libro III normaba los procedimientos de conciliación y arbitraje entre empleadores y trabajadores.

72 El referido proyecto se puede encontrar en: "Proyecto de Código del Trabajo i de la Previsión Social", Boletín Especial de la Oficina del Trabajo, №17, Santiago, 1921, pp. 109-164.

73 “Proyecto del Código del Trabajo i de la Previsión Social”, Boletín Especial de la Oficina del Trabajo, № 17, Santiago, 1921 , pp. 3 - 21.

${ }^{74}$ González discutió la propuesta al interior de la Sociedad Médica de Santiago, donde tuvo oposición a que esta iniciativa se presentara como proyecto de Ley. Esto se puede observar en el Boletín del Sindicato Médico del año
} 
precariedad en que vivía la mayoría de la población y la afectación al hogar que generaba que el jefe de hogar tuviera que dejar de trabajar; y, (ii) que la creación de la Caja ayudaría a financiar las atenciones sanitarias en la Beneficencia Pública y, de esa manera, mejorar las aflictivas condiciones hospitalarias del país ${ }^{75}$.

La previsión social fue un tema central en el Congreso de la Beneficencia Pública realizado en 1922. La presentación conjunta de Moisés Poblete Troncoso y Ezequiel González Cortés titulada "Seguros obreros contra accidentes, enfermedades, invalidez y vejez, como fuente de recursos para la Beneficencia" exponía las razones que motivaban la creación de un órgano previsional: (i) la necesidad de establecer mecanismos de seguros ante los riesgos del trabajo para los obreros y contribuir al financiamiento de la Beneficencia Pública para la atención de estos; (ii) el incremento que se había observado en los accidentes, enfermedades y situaciones de invalidez laboral de los obreros; (iii) la necesidad de establecer un seguro social para mantener la paz social y armonía entre obreros y patrones; y (iv) "la justificación moral y filosófica de los seguros sociales" se encontraba en la existencia de los riesgos del trabajo, ante lo cual era necesario una organización colectiva para la asistencia y previsión social ${ }^{76}$.

El Congreso de la Beneficencia Pública de 1922 concluyó que era urgente la necesidad de implementación de los seguros sociales obligatorios en Chile y acordó "solicitar del Congreso el pronto despacho de la parte del Proyecto del Código del Trabajo relacionada con los seguros sociales o del proyecto sobre la misma materia del Dr. González Cortes, con las modificaciones que estimen necesarias"77.

Aún con la presentación de propuestas de ley, las elaboraciones de expertos y los resultados del Congreso de la Beneficencia Pública, para 1923 el Parlamento todavía no abría la discusión sobre seguros sociales para los trabajadores. Así, en abril de ese año, el Presidente Alessandri informó al Congreso Nacional que el Consejo de Estado había decidido que el proyecto de seguros sociales presentado por González fuera discutido en el periodo de sesiones extraordinarias de 1923. Tres razones habrían llevado a Alessandri a promover el proyecto de González Cortés: (i) la similitud entre ambas propuestas; (ii) que, del proyecto de Poblete, sobre Código del Trabajo, se habían discutido los Libros I a III y no el IV, que planteaba la creación de la Caja; y (iii) que el proyecto de González presentaba a la época mayor respaldo político ${ }^{78}$, lo

1926, citado en: Molina, Carlos. 2007. Una mirada historiográfica acerca del desarrollo de institucionalidad sanitaria chilena: 1889-1989, Universidad de Chile, Tesis para optar al grado de Magister en Historia, Santiago, pp. 66 - 67.

75 “Proyecto sobre Seguro Obligatorio", Boletín de la Oficina del Trabajo, № 21, Santiago, 1921, pp. 254 - 259.

76 Poblete, Moisés y González, Exequiel, "Seguros sociales contra accidentes, enfermedades, invalidez y vejez como fuente de recursos para la Beneficencia", Revista de la Beneficencia Pública, № 1, Santiago, 1922, pp. 117 - 152.

77 Poblete, Moisés y González, Exequiel, "Seguros sociales contra accidentes, enfermedades, invalidez y vejez como fuente de recursos para la Beneficencia", Revista de la Beneficencia Pública, № 1, Santiago, 1922, pp. pp. 151 - 152. 78 En Marzo de 1923 el Diputado Artemio Gutiérrez, a nombre de la Comisión de Asistencia Pública y Culto solicitó a la Mesa Directiva de la Cámara que el proyecto de González se pusiera en tabla. Luego el Senador Ismael Valdés Valdés y el Diputado Fernando Jaramillo hicieron similar petición a nombre de la Junta de Beneficencia de Santiago. 
que daba a Alessandri la posibilidad de aprobar con mayor rapidez una ley en un tema de su máximo interés.

A septiembre de 1924 la propuesta de creación del seguro social estaba paralizada en el Congreso, al igual que variados otros proyectos. La situación a la fecha era de una crisis política en desarrollo ${ }^{79}$ como consecuencia directa del surgimiento de un movimiento de militares que presionaba al gobierno para que se atendieran sus reivindicaciones económicas. A ellas luego agregaron demandas que excedían las cuestiones propiamente militares, como aspectos referidos a impuestos, leyes sociales y laborales. La moción de dieta parlamentaria que se discutía en el Senado encendió los ánimos. Alessandri la catalogó como: “Aspiración justa, necesaria, indispensable, pero profundamente inoportuna en momentos de hambre, miseria y angustia nacional" ${ }^{80}$. La moción ocasionó que un grupo de 50 oficiales de la guarnición de Santiago en las tribunas del Senado expresara su molestia por la situación mediante la sonajera de sus sables. En ese contexto, el debutante ministro del Interior, general Luis Altamirano, presentó una lista de 16 proyectos de ley que requerían tramitación urgente en el Congreso, las que fueron aprobadas en la sesión del 8 de Septiembre de 1924. Entre ellos se incluía el proyecto sobre "Seguro Obligatorio de Enfermedad e Invalidez" ${ }^{81}$.

\section{La Caja de Empleados Públicos}

En el ámbito previsional de los empleados públicos, luego de la reforma a las jubilaciones establecida por Ley №1.146 de 1898, el tema siguió en la discusión política durante las primeras décadas del siglo XX. El presidente Germán Riesco presentó un proyecto de Caja de Retiro para los empleados fiscales en 1903, que tenía características similares a uno presentado en 1887, sobre "Caja de Retiro i Seguros para empleados públicos", y aunque fue aprobado en la Cámara de Diputados, no lo fue en el Senado. Luego, desde la Cámara de Diputados surgieron dos

Ver: DSCD, Sesión 155 Extraordinaria, 23 de marzo de 1923, p. 2059; DSCD, Sesión 19 Ordinaria, 17 de junio de 1924, pp. 551 - 552.

${ }^{79}$ A 1924 variadas iniciativas de ley que constituían aspectos centrales del programa de gobierno de Alessandri estaban detenidas o con lenta tramitación en el Congreso. A ello se añadió la conformación de un Comité Militar, compuesto principalmente por oficiales jóvenes del Ejercito, al que luego se unieron miembros de la Armada. Ellos presionaban por mejoras en su debilitada situación económica y aspectos institucionales. Las tensiones entre el Comité Militar, que fue capturando creciente apoyo en las filas castrenses y en el que Carlos Ibáñez del Campo fue adquiriendo crecientes roles de liderazgo, desataron una crisis política de gran significación. Ante la situación, el presidente Alessandri reestructuró su gabinete y designó como ministro del Interior al General Luis Altamirano. El nuevo gabinete quedó integrado por dos miembros del Ejército, uno de la Armada y tres civiles en los restantes ministerios.

80 Donoso, Armando. 1934. "Conversaciones con don Arturo Alessandri", Santiago, Biblioteca Ercilla, 1934, p. 82.

81 Luego de la aprobación de las leyes reclamadas, el Comité Militar exigió la disolución del Congreso, cuestión que el presidente no estuvo dispuesto a aceptar. Renunció al cargo el 8 de septiembre de 1924, asumiendo como vicepresidente de la Republica el General Altamirano, quien junto a los otros ministros militares del gabinete constituyó una Junta de Gobierno y disolvió el Congreso. Antes de la disolución, el Congreso rechazó la renuncia del Presidente, concediéndole un permiso de ausencia de seis meses. 
iniciativas sobre el mismo tema durante los primeros años del siglo XX ${ }^{82}$. En 1914 un nuevo proyecto de Caja de Retiro para los empleados públicos fue enviado a trámite legislativo por el Presidente Ramón Barros Luco, que fue discutido en agosto de ese año ${ }^{83}$.

Una nueva propuesta surgió en 1918 cuando el presidente Juan Luis Sanfuentes mandató al ministro de Hacienda, Luis Claro Solar, a crear una comisión para redactar la propuesta de Caja de Retiros de Empleados Públicos. La comisión quedó integrada por Eugenio Frías Collao, director de la Oficina del Trabajo, Julio Molina Núñez, secretario de la Caja de Retiros y Previsión Social de los Ferrocarriles del Estado, a los que luego se sumaron Eduardo Amengual, jefe de Sección de la Oficina Central de Estadísticas, y Arturo Clement, Actuario de la Caja de Retiros y Previsión Social de los Ferrocarriles del Estado ${ }^{84}$.

El trabajo de la Comisión se recogió en un proyecto de ley que el gobierno envió a trámite parlamentario en agosto de 1918. El mensaje presidencial establecía que la iniciativa buscaba: (i) contener el gasto en jubilaciones porque implicaba una carga monetaria importante al Estado, los que se incrementaban cada año; (ii) establecer una previsión "científicamente organizada e impuesta por lei"; y (iii) mejorar el sistema de jubilaciones, ya que las pensiones en la generalidad se pagaban por pocos años y, cuando el beneficiado fallecía, su familia quedaba sin ingresos ${ }^{85}$. El proyecto establecía que el financiamiento de la Caja estaría constituido por un aporte inicial de capital por parte del Estado, por el aporte de un porcentaje del sueldo de los trabajadores y por las ganancias producidas por las inversiones que hiciera la Caja. Asimismo, proponía que los trabajadores tuviesen cuentas individuales en que se registrarían sus aportes y saldos.

En 1919 se formuló un nuevo proyecto de Caja de Retiro para Empleados Públicos, siendo una iniciativa ideada por el secretario de Comisiones del Senado Manuel Novoa ${ }^{86}$. Después, en marzo de 1920, desde el gobierno designaron otra Comisión para estudiar los proyectos de Caja de Retiro y crearon una nueva propuesta, la cual estuvo inspirada en la iniciativa gubernamental de $1918^{87}$.

A poco de asumir Alessandri, el 1 de marzo de 1921, el Senador Eliodoro Yáñez presentó otra propuesta denominada "Caja Nacional de Jubilaciones, Montepío y Seguro de Vida de los Empleados Públicos del Orden Civil", recogiendo este proyecto muy significativamente lo formulado por Manuel Novoa en $1919^{88}$. El proyecto consideraba pensiones de jubilación y

\footnotetext{
82 DSS, Sesión 60 Ordinaria, 11 de septiembre de 1914, p. 876.

83 DSS, Sesión 46 Ordinaria, 24 de agosto de 1914, pp. 674 - 679.

84 "Oficio de la Oficina del Trabajo al Ministerio de Hacienda del 16 de julio de 1918", Boletín de la Oficina del Trabajo, $n^{\circ} 11$, Santiago, 1918, p. 158.

85 "Texto del mensaje y proyecto de ley relativos a la creación de la Caja de Retiro de Empleados Públicos", Boletín de la Oficina del Trabajo, n 11, Santiago, 1918, pp. 160 - 183.

86 "Caja de Retiro y de Previsión para los Empleados Públicos", El Mercurio, Santiago, 1 de abril de 1922, p. 3.

87 "Caja de Retiro y de Previsión para los Empleados Públicos", El Mercurio, Santiago, 1 de abril de 1922, p. 3.

88 DSS, Sesión 7 Extraordinaria, 5 de abril de 1922, p. 164.
} 
retiro, seguros de vida, dación de montepíos, prestaciones médicas, préstamos de auxilio económico y habitacionales. El financiamiento provendría del aporte del $10 \%$ del sueldo del empleado, de los intereses que percibiera la Caja producto de sus operaciones y aportes del Estado en situaciones específicas.

El proyecto Yáñez-Novoa fue aprobado por la comisión especial del Senado creada para estudiar la propuesta. En su aprobación, el Comité argumentó que la propuesta permitía: 1) "liberar al presupuesto de la Nación del pesado gravamen que le impone el defectuoso régimen imperante"; 2) mejorar las pensiones que "jeneralmente son reducidas, apenas si bastan para permitir al empleado y a su familia vivir escapando de los límites de la indigencia"; y 3) entregar beneficios que permitirían resolver la situación en que quedaba la familiar del empleado que fallecía, pues en ese momento se acababa el derecho a pensión del Estado y "queda privada del único recurso de que disponía para atender a su sustento" ${ }^{89}$. Los empleados públicos proclamaron que "el proyecto viene a satisfacer una necesidad sentida ... por todos los servidores de la Nación, ... no solamente en su propia persona, sino que también el porvenir de sus familias con la creación del Montepío Civil" ${ }^{90}$. Aun así, el proyecto recibió críticas por centrarse en una "doctrina ... anticuada, ya caída en desuso ... (y) que no beneficia por igual a todos los imponentes de la Caja" y porque entregaría beneficios que la Caja no podría financiar ${ }^{91}$.

El proyecto fue discutido en periodos de mayo de 1921, mayo de 1922 y, luego, en agosto de 1924. Después de los sucesos de septiembre de 1924, con el presidente Alessandri ausente y un Congreso disuelto, la Junta de Gobierno de los Generales Altamirano y Bennet y el Almirante Nef conformó una comisión integrada por Moisés Poblete, Julio Molina Núñez y el actuario Andrés Jilmont para elaborar un proyecto de jubilaciones de los empleados públicos ${ }^{92}$.

Una nueva Junta de Gobierno, integrada por Emilio Bello Codesido, el General Dartnell y el Almirante Ward ${ }^{93}$, tomó el poder el 23 de enero de 1925. Esta, en marzo de ese año, encomendó a Julio Molina la preparación del proyecto sobre Caja de Retiro de los Empleados Públicos Civiles, quien entregó su propuesta a mediados de ese mes, la que fue aprobada por dos miembros de la Junta de Gobierno, pero no por su presidente, Emilio Bello Codesido ${ }^{94}$.

\footnotetext{
89 DSS, Sesión 1 Extraordinaria, 23 de mayo de 1921, pp. 2120-2121.

90 "Los empleados públicos y la caja de retiro", La Nación, 23 de abril de 1922, p. 19.

${ }^{91}$ Clement, Arturo y Molina, Julio, “Caja de Retiro y de Previsión Social para los Empleados Públicos", El Mercurio, 1 de abril de 1922, p. 3.

92 “Una Caja de retiro y previsión para los empleados públicos civiles”, La Nación, 19 diciembre 1924, p. 13.

${ }_{93}$ Esta Junta de Gobierno llamó a Alessandri a regresar al país y reasumir sus funciones.

${ }^{94}$ Molina, Julio. 1924. Creación de una verdadera Caja de Retiro y de Previsión Social para los Empleados Públicos Civiles, Santiago, Imprenta Universitaria, p. 4.
} 
Alessandri retomó el cargo el 20 de marzo de $1925^{95}$. La Caja de Empleados Públicos fue creada mediante Decreto Ley №454 promulgado el 14 de Julio de 1925, recogiendo la propuesta de Yáñez-Novoa ${ }^{96}$. Incluyó a los empleados de la administración civil del Estado, de las empresas periodísticas y a las familias de los beneficiarios. Estableció "pagos de pensiones de jubilación a los empleados que cesen en el desempeño de sus cargos, ... seguro de vida, ... un fondo de montepío, ... la formación de instituciones de ahorro y de crédito y de sociedades cooperativas entre el personal” ${ }^{\prime 97}$.

\section{La Caja de Empleados Particulares}

La idea de establecer un sistema previsional para los empleados particulares tiene su origen en el Programa Mínimo de Legislación Social promovido por Valentín Letelier y aprobada por la Convención Nacional del Partido Radical de enero de 1906. Aquella proclama recomendaba establecer, entre otras, una "legislación sobre accidentes del trabajo" e instituir en el Estado "Cajas de seguros, de invalidez, de viudedad y de orfandad en favor de los marineros, soldados, policía, camineros, y otros empleados análogos que se inhabilitan en el servicio o que perezcan por accidentes del mismo"98. A partir de ello, Asambleas Radicales de Antofagasta, en $1916^{99} \mathrm{y}$ de Valparaíso, en $1918^{100}$, plantearon propuestas en el mismo sentido.

La asunción de Alessandri a la presidencia, con un programa que incluía reformas sociales, permitió instalar contenidos que ya se planteaban en el programa mínimo de 1906 en la agenda política de la época. Hinojosa ${ }^{101}$ relata que representantes de la Federación de Empleados de Antofagasta le entregaron a Alessandri, cuando visitó esa ciudad en calidad de Presidente Electo en noviembre de 1920, un memorándum de peticiones de políticas públicas, entre las que estuvo la creación de una Caja de Retiro de los Empleados Particulares. Dado que esta iniciativa no alcanzó a ser incluida entre las reformas sociales propuestas por Alessandri al Parlamento en junio de 1921, el proyecto previsional para empleados particulares fue presentado como moción parlamentaria.

El senador radical por Tarapacá, Ramón Briones Luco, presentó el 12 de junio de 1921 un proyecto de ley sobre regulación de las condiciones de trabajo de los empleados particulares,

\footnotetext{
95 Alessandri renunciaría definitivamente a la Presidencia de la República el 1 de octubre de 1925, 84 días antes de concluir su mandato constitucional, por fuertes tensiones entre él y los militares encabezados por Carlos Ibáñez del Campo, Ministro de Guerra a la sazón.

96 Molina. 1924, Creación de, p. 4.

${ }^{97}$ Artículo 1 de: República de Chile, Decreto Lei N454, 15 de Julio de 1925. Recuperado de: http://bcn.cl/2tsq7 (Consultado el 30 de abril de 2021).

98 Hinojosa. 1967, La Caja de, p. 10.

99 Hinojosa. 1967, El libro de, p. 110.

100 "Ahorro, previsión y amparado para los empleados y obreros", El Mercurio, Santiago, 14 de octubre de 1918, p. 16.

101 Hinojosa. 1967, La Caja de, pp. 16-18; Hinojosa. 1967, El libro de, p. 89.
} 
el que contenía la creación de una institución de retiro para dichos trabajadores. Briones Luco argumentó que el electorado de Tarapacá pedía esa ley debido a que: 1) los empleados particulares no tenían una ley que regulara su trabajo, quedando a merced de la voluntad de sus patrones; y 2) que "el empleado particular de modestos recursos está en condiciones más desmedradas que el obrero" al no tener leyes o programas de protección social. Entonces, para mejorar su situación, se hacía necesario legislar sobre los empleados y sus condiciones de trabajo ${ }^{102}$.

Otra iniciativa fue presentada el mismo 1921 por el médico y diputado radical por Antofagasta Leonardo Guzmán, en conjunto con otros diputados, y con la colaboración de la Federación de Empleados de Antofagasta. ${ }^{103}$. La argumentación de Guzmán se centró en: 1) que los empleados particulares estaban siendo dejados de lado en un contexto en que se estaba legislando en favor de los "desvalidos"; 2) que faltaba una legislación que regulara sus condiciones de trabajo; y 3) que los empleados tenían una situación material de vida "no menos difícil" que los obreros ${ }^{104}$.

Luego de cuatro años de tramitación, la Cámara de Diputados lo aprobó el 3 de septiembre de 1924 y, luego, fue incluido en los 16 proyectos de ley propuestos por el ministro del Interior, General Luis Altamirano, que fueron aprobados por el Senado el 8 de septiembre de $1924^{105}$.

La Ley de los Empleados Particulares fue promulgada como Ley №4.059 el 8 de septiembre de 1924. Establecía que en la Caja Nacional de Ahorros y Caja de Ahorros de Santiago se "abrirán cuentas corrientes especiales, que se llamará de ahorro y previsión de empleados" (art. 20), donde "todo patrón estará obligado a depositar mensualmente, en cuenta corriente especial de ahorro y previsión de empleados, a nombre de cada empleado" (art.22). A su vez, las Cajas debían entregar "a los empleados, previa verificación de su calidad, libretas de cuenta corriente" (art.21), en la que estos pudieran llevar registros de sus movimientos y saldos. De este modo, los retiros por haber cumplido la edad mínima o haber devenido en incapacidad para trabajar se hacían contra "Ios fondos que se hubieren acumulado en su respectiva cuenta de ahorro y previsión” (art.24). Todo ello confería al esquema original de jubilaciones y pensiones de los empleados particulares el carácter de un sistema de capitalización individual ${ }^{106}$.

Luego, variadas intervenciones del poder ejecutivo, en corto tiempo y con el Congreso suspendido, fueron reformulando las disposiciones de la Ley №4.059 en varias ocasiones entre

\footnotetext{
102 DSS, Sesión 11 Ordinaria, 15 de junio de 1921, p. 211.

103 Hinojosa. 1967, El libro de, pp. 101-102; Hinojosa. 1967, La Caja de, pp. 20-22.

${ }^{104}$ DSCD, Sesión 55 ordinaria, 18 de agosto de 1921, p. 1751.

105 Bennet, Juan Pablo. 1926. "La Revolución del 5 de Septiembre de 1924", Santiago, Barcells.

${ }^{106}$ Esta Ley se puede encontrar en: República de Chile, Ley N4059, 8 de septiembre de 1924. Recuperado de: http://bcn.cl/2pgsn (consultado el 30 de abril de 2021).
} 
1924 y 1925 . Finalmente, el DFL №857 ${ }^{107}$, promulgado el 11 de noviembre de 1925 por el vicepresidente de la República, Luis Barros Borgoño, estableció "el testo de la Lei de Empleados Particulares", derogó la Ley №4.059 (art. 59), estableció disposiciones sobre el fondo de retiro y seguro, y reglamentó la administración del Fondo de Retiro de los Empleados Particulares. Un elemento destacable de esta normativa fue dar la posibilidad a que industrias, comercios, instituciones o secciones especiales pudiesen generar sus propios organismos de previsión social ${ }^{108}$.

En los siete años siguiente a la autorización otorgada por el Decreto Ley № 857 de 1925 se crearon 18 órganos previsionales para segmentos específicos de empleados particulares ${ }^{109}$, pero la Junta de Gobierno de la época, mediante Decreto Ley 178 de 1932, consideró que éstos no habían concedido "servicios superiores a los concedidos por el organismo central", dada "su natural incapacidad financiera", por lo que ordenó "traspasar los haberes de sus imponentes a la Caja de Previsión de Empleados Particulares" ${ }^{110}$. Veintiún días después, el 4 de Agosto de 1932, el gobierno provisional de Carlos Dávila expidió el Decreto Ley №369, que autorizó a los órganos previsionales creados previamente al "Decreto Ley №178 de 11 de Julio de 1932 ... y que otorguen mayores beneficios que la Caja de Previsión de Empleados Particulares" a mantener su funcionamiento, aunque igualmente debían traspasar sus haberes a la Caja "cuando así lo resuelva el Presidente de la República a petición de la mayoría de los imponentes de cada organismo o sección de previsión". Estableció, además, que no se crearían nuevos organismos previsionales (art. 3ํ), pero esa norma sería nuevamente revisada en lo sucesivo. Así, a 1941, solo en el ámbito de los empleados particulares, por diversas leyes y decretos, se habían creado 32 Cajas de Previsión para distintos segmentos de trabajadores con los siguientes regímenes financieros: " 2 de capitalización colectiva, 7 de régimen mixto y 23 de capitalización individual"111.

La inestabilidad política del segundo semestre de $1932^{112}$, con el Congreso suspendido y la inclinación de sucesivas Juntas a congraciarse con segmentos de trabajadores, puede ser

\footnotetext{
107 El artículo 60 del DFL 857 señala que "esta lei empezará a rejir desde su publicación en el Diario Oficial", lo que aconteció el 16 de Diciembre de 1925.

${ }^{108}$ Esto es establecido en el artículo 16 de la Ley de Empleados Particulares. Ver: República de Chile, DFL 857, 11 de noviembre de 1925. Recuperado de: http://bcn.cl/2p35k (consultado el 30 de abril de 2021).

${ }^{109}$ Campos, Alfonso. 1941. Hacia una Política Preventiva de los Seguros Sociales, Universidad de Chile, Tesis para optar al grado de Licenciado en Ciencias Jurídicas, p. 51.

${ }^{110}$ El Decreto Ley 178, de 1932, se puede encontrar en: República de Chile. 1958-1959. Repertorio de legislación y jurisprudencia chilenas: Código del Trabajo, Santiago, Editorial Jurídica, pp. 180 - 181.

111 Campos. 1941, Hacia una, p. 51.

${ }^{112}$ El 4 de Julio de 1932 el presidente Juan Esteban Montero Rodríguez fue derrocado por un movimiento cívico militar que proclamó la Republica Socialista de Chile. El General Arturo Puga fue designado Jefe de la Junta de Gobierno, que también integraban Eugenio Matte y Carlos Dávila Espinoza. Doce días más tarde, asumió como presidente Provisional de la República Socialista. Dávila renunció el 13 de septiembre de 1932, asumiendo el cargo el ministro del Interior, General Bartolomé Blanche Espejo, quién a su vez renunció el 2 de Octubre de 1932. El presidente de la Corte Suprema, Abraham Oyanedel Urrutia, asumió como vicepresidente de la República, llamó a
} 
asociada a las contradictorias normas que se dictaron en la época sobre la previsión de los empleados particulares. Asimismo, las normas posteriores, que también buscaron no contradecir las demandas de grupos específicos de empleados en referencia a temas previsionales, llevaron a una proliferación de este tipo de órganos.

\section{La Reforma de 1952}

A inicios de la década de 1950 se plantearon sendas reformas a dos de las principales Cajas de seguridad social: a la del Seguro Obrero Obligatorio y a la de Empleados Particulares. Las propuestas apuntaron a una ampliación de la cobertura y a la entrega de mayores beneficios a los afiliados. Las discusiones por reformas a la seguridad social provenían desde fines de la década de 1930. En 1939 presidente Pedro Aguirre Cerda, planteó la necesidad de modificar las leyes 4.054 y 4.055 para reorganizar el sistema de seguro social frente a la enfermedad, accidentes, invalidez laboral y vejez. En febrero de 1940, Aguirre conformó una Comisión que debía elaborar un proyecto sobre la materia, la que estuvo integrada por médicos y técnicos ${ }^{113}$. En su mensaje al Congreso, el presidente hacía una dura crítica al funcionamiento del sistema previsional vigente a la época:

"En Chile, este Seguro se desenvuelve en condiciones sensiblemente deficientes. Pueden señalarse como sus más resaltantes defectos, su organización heterogénea y la deficiencia de las prestaciones que conceden la mayor parte de las instituciones aseguradoras.

Cuarenta y cuatro Cajas, organizadas bajo regímenes muy diversos, atienden la previsión de los asalariados. Hay instituciones ...que se ajustan casi completamente a las concepciones modernas de Previsión Social y de otra que apenas constituyen Cajas de Ahorro individual que no amparan al imponente contra los más elementales riesgos sociales" (Aguirre, 1941: $134)^{114}$.

En el mensaje, el presidente también expuso su concepción de la seguridad social:

“El objetivo fundamental del Seguro Social, es proveer a la conservación e incremento, recuperación y reemplazo, en las formas científicas más adecuadas y modernas, del capital humano, a fin de mejorar las condiciones y la composición demográfica de la población. En consecuencia, el Seguro Social debe prevenir y recuperar cuanto es posible, o indemnizar, en todo caso, el daño económico ocasionado por cualquiera pérdida de la capacidad de

elecciones en las que resultó electo Arturo Alessandri Palma, asumiendo el cargo de presidente de la República el 24 de Diciembre de 1932.

${ }^{113}$ Entre ellos estuvo el ministro de Salubridad de la época, Salvador Allende, Exequiel González Cortés, Julio Bustos, Hernán Santa Cruz. Ver: DSCD, Sesión 4 Ordinaria, 10 de junio de 1941, pp. 133 - 136.

${ }^{114}$ DSCD, Sesión 4 Ordinaria, 10 de junio de 1941, p. 134. 
trabajo, ya sea parcial, temporal, permanente o total, y ya sea que esta se produzca por razones inherentes al trabajo o a la estructura económica de la sociedad" ${ }^{115}$.

Una de las más duras y reiteradas críticas que recibía la Caja del Seguro Obligatorio era "la insignificancia del monto de las pensiones por vejez", lo que era atribuido a que la cotización ascendía "solamente al $2 \%$ de los salarios (3\% en determinados casos)" ${ }^{116}$, y a que "se ocupan en gastos médicos y administrativos los recursos destinados al financiamiento de las pensiones"117. Las bajas pensiones también estaban asociadas a la política de inversiones de la Caja, la que era duramente criticada en la época:

"La experiencia de la política de capitalización de la Caja de Seguro Obligatorio había sido desastrosa. En efecto, los bienes de la Caja de Seguro Obligatorio rendían un interés que ya era insignificante si se consideraba el dinero en ellos invertido, y que resultaba francamente despreciable si él se calculaba sobre la base del valor actual de esta inversión [...] Las inversiones no fueron nunca resueltas por los administradores o vicepresidentes por si solo sino que contando con la anuencia de Consejeros numerosos constituidos por personas de las más diversas ideologías y técnicas. Es necesario, pues, concluir que o bien la inepcia financiera es una característica suficiente generalizada entre quienes han dirigido el país o bien son otras las razones que determinan el mal resultado de este tipo de inversiones de capitalización" ${ }^{118}$.

Junto con buscar incrementar el monto de las pensiones de los obreros, el proyecto de 1941 también planteaba el:

“[...] aumento de los subsidios de incapacidad y racionalización de las pensiones de invalidez y de vejez [...] establecimiento del seguro de orfandad, de viudedad y de cesantía; obligatoriedad del seguro contra accidentes del trabajo y enfermedades profesionales, entregándole a una institución de previsión, excluyendo a las compañías de seguros de

\footnotetext{
115 DSCD, Sesión 4 Ordinaria, 10 de junio de 1941, pp.133 - 136.

${ }^{116} \mathrm{El}$ informe del Consejo Nacional de Economía, donde se exponía esta crítica, es, presumiblemente, de 1946. Señalaba que el proyecto de reforma "sin constituir un ideal" era un avance pues "les garantizaba, a lo menos, una protección suficiente para librarlos de la indigencia". El informe reconocía que, para alcanzar ese fin, la propuesta del gobierno, "las imposiciones personales" del trabajador "se eleven al $4 \%$ de los salarios, es decir al doble de aporte actual". Ver: Consejo Nacional de Economía. (s/f). Informe de la Comisión del Trabajo Salarios y Previsión Social del Consejo Nacional de Economía, sobre el Proyecto de Reforma a las Leyes 4054 y 4055, Santiago, Consejo Nacional de Economía, Secretaría General, pp. 2 - 3.

117 Consejo Nacional de Economía. s/f. Informe de la Comisión del Trabajo Salarios y Previsión Social del Consejo Nacional de Economía, sobre el Proyecto de Reforma a las Leyes 4054 y 4055, Santiago, Consejo Nacional de Economía, Secretaría General, p. 5.

118 Mardones, Jorge. 1954. La reforma de la seguridad social de los obreros. Motivos de la Ley 10.383, Santiago, Editorial Jurídica de Chile, p. 37.
} 
carácter comercial, y otorgamiento de subsidios e indemnizaciones de tipo vital contra este riesgo" 119 .

Esta iniciativa no llegó a ser discutida mayormente durante el gobierno de Aguirre, teniendo una lenta tramitación por varios años, siendo retomada por el presidente Gabriel González Videla al asignarle, en 1950, "urgencia para el despacho del proyecto de ley que reforma las Leyes $\mathrm{N}^{\text {os }} 4.054$ y 4.055" ${ }^{120}$. Al asignarle urgencia, el gobierno introdujo sensibles modificaciones al "proyecto iniciado en 1941", por lo que, "con las modificaciones que ha tenido y las nuevas materias incorporadas en él", el proyecto de 1950 "tiene otros alcances y bases diferentes"121. Mardones refrenda esta impresión, señalando que "había transcurrido entonces mucho tiempo desde el momento en que se elaborara el proyecto (de 1941) que sirvió de base de estudio y había por eso mucho que modificar"122.

El proyecto de 1941 mantenía el esquema de capitalización individual para el retiro y jubilación, lo que sufrió un cambio drástico en la discusión de inicios de la década de 1950, al pasar a constituirse como un esquema de reparto. Dos fueron los argumentos para producir este cambio: 1) la inefectividad de la política de inversiones de la caja y; 2) la inflación de la época. Sobre el primer argumento, aparte de las opiniones recién citadas del ministro Mardones, en el debate parlamentario se señaló que las:

“... inversiones en bonos, fundos, edificios de renta, etc., no tienen ningún significado para los asegurados; inclusive, se han convertido en un peso gravísimo para la economía del país, pues implican una capitalización no productiva que gravita sobre el sistema económico y financiero de Chile" ${ }^{123}$.

Respecto del segundo argumento, en la discusión del Congreso se indicó que "el régimen de capitalización ha perdido y pierde con razón, su eficacia en todos los países que no tienen moneda estable [...] como ha ocurrido en nuestro país" ${ }^{124}$. En la revista Panorama Económico se ahondó en el tema, señalando que:

“... en la práctica, en lo que a Chile se refiere, el sistema de capitalización ha sido frustrado ... también, porque el proceso inflacionista ha resultado de un corrosivo más poderoso que

\footnotetext{
119 DSCD, Sesión 4 Ordinaria, 10 de junio de 1941, p. 136.

120 DSCD, Sesión 8 Extraordinaria, 23 de noviembre de 1950, p. 496.

121 Biblioteca del Congreso Nacional, Historia de la Ley 10.383, Santiago, 2020, p. 25. Recuperado de: www.bcn.cl (consultado el 20 de noviembre de 2020).

122 Mardones. 1954, La reforma, p. 20.

123 Biblioteca del Congreso Nacional, Historia de la Ley 10.383, Santiago, 2020, p. 25. Recuperado de: www.bcn.cl (consultado el 20 de noviembre de 2020).

${ }^{124}$ Biblioteca del Congreso Nacional, Historia de la Ley 10.383, Santiago, 2020, p. 25. Recuperado de: www.bcn.cl (consultado el 20 de noviembre de 2020).
} 
todas las medidas pseudoprotectoras que se pretendía tomar a través del resguardo proveído por edificios, fundos y otros bienes duraderos"125.

Este proyecto fue ampliamente discutido entre 1950 y 1952 en varias comisiones de la Cámara de Diputados y del Senado. Intervinieron en su discusión técnicos, médicos y trabajadores. Por ejemplo, en una Comisión que estudió el proyecto en la Cámara de Diputados en octubre y noviembre de 1950 participaron Julio Bustos, Francisco Pérez Lavín y Moisés Poblete, todos técnicos y conocedores del sistema previsional ${ }^{126}$. Por su parte, una Comisión de Senado que estudio el proyecto en junio-julio de 1951 tuvo participación de médicos y técnicos conocedores del sistema previsional como Juan Hepp, Julio Bustos, Mario Arteaga Infante y, además, representantes del Colegio Médico, jefes de servicios y funcionarios técnicos del sistema ${ }^{127}$.

El proyecto fue finalmente aprobado como Ley №10.383 ${ }^{128}$ y promulgada el 8 de agosto de 1952. Transformó la Caja del Seguro Obligatorio en el Servicio de Seguro Social, modificó el esquema de retiro y jubilación de capitalización individual a reparto y estableció como "obligatorio el seguro contra los riesgos de enfermedad, invalidez, vejez y muerte para ... todos los obreros que ganen un salario, ... los obreros postulantes o aprendices de cualquier trabajo, industria u ocupación ... y trabajadores independientes" (art. 1으 y 2ª).

Por otro lado, en la década de 1940, las críticas al sistema previsional se hacían más ostensibles, las que no solo apuntaban al sistema que cubría a los obreros, sino que también se hacía extensiva a los empleados. La revista Panorama Económico exponía que problemas que había en el sistema en su conjunto:

"La legislación de previsión social de Chile ha sido dictada en forma dispersa y heterogénea. Se consultan distintos regímenes para los diversos grupos asalariados, con las consecuencias de que cubren los riesgos en forma deficiente, de que no hay continuidad en la previsión, los recursos son diferentes en su monto y en su origen y la estructura financiera de los sistemas es diversa y precaria"129.

La Caja de Previsión de los Empleados Particulares era más bien un fondo de ahorro obligatorio, constituido por aportes individuales que, sumados a los aportes del empleador y a una indemnización por años de servicios, el trabajador podía retirar al momento del cese de su vida laboral, pero no era un sistema que otorgara una pensión periódica de jubilación.

\footnotetext{
125 "La seguridad social chilena recupera el paso", Panorama Económico, n 39, septiembre de 1951, p. 343.

126 DSCD, Sesión 8 extraordinaria, 23 de noviembre de 1950, p. 499.

127 Diario de Sesiones de Senadores, [ en adelante DSS], Sesión 29 Ordinaria, 4 de septiembre de 1951, p. 1341.

128 La Ley №10.383 también creó el Servicio Nacional de Salud en el artículo 62 y estableció las bases de su funcionamiento en los artículos siguientes.

129 “Necesidad de reformar las leyes 4.054 y 4.055”, Panorama Económico, № 10, febrero de 1948, p. 37.
} 
El origen de la reforma a la "Lei de Empleados Particulares" de 1924 estuvo en un proyecto presentado por Diputados en la Cámara en 1948, el cual en su idea original abordaba la jubilación de los empleados de las empresas de compañías eléctricas ${ }^{130}$. Después de un tiempo sin mayores avances en su discusión, en julio de 1950, el gobierno puso urgencia a la tramitación del proyecto ${ }^{131}$. Fue debatido y modificado en la Comisión de Trabajo y Legislación Social de la Cámara a partir de un contraproyecto presentado por el ministro de Salubridad Jorge Mardones Restat, pasando a ser un proyecto para "conceder jubilación a los empleados de las Empresas de Utilidad Pública" ${ }^{132}$ Con ello, el foco del proyecto se ampliaba para abarcar a muchos más empleados.

Entre los temas centrales en discusión estuvo: primero, la necesidad de no continuar generando regímenes previsionales y, segundo, si mantener la capitalización individual o se pasaría a un sistema de reparto para los empleados particulares. Sobre el primer tema, Panorama Económico señalaba que:

“... las fuerzas de la producción y del comercio han llamado reiteradamente la atención de los Poderes Públicos a la necesidad imperiosa de no continuar legislando en materia de previsión sin un plan general bien concebido, encaminado a concluir con la multiplicidad de regímenes que actualmente existe en esta materia, lo que aparte de introducir una verdadera anarquía, constituye un factor permanente de presión inflacionista, determinado por la justa aspiración de los diferentes grupos de asalariados por conseguir los mismos beneficios que otros ya obtuvieron" ${ }^{133}$.

Sobre el segundo tema, la misma revista planteaba que:

“... tampoco puede explicarse que al reformar la legislación de los empleados particulares se insistía en un régimen de capitalización en los precisos momentos en que está por convertirme en ley otro proyecto de este mismo carácter para los obreros, que obedece al sistema de reparto" ${ }^{134}$.

En el debate legislativo afloró una tensión entre la extensión de beneficios a todos los empleados particulares y la real capacidad de financiamiento de ello. Así, mientras la Comisión de Trabajo y Previsión Social de la Cámara se pronunció en favor de "la extensión, sin discriminación alguna, del beneficio de jubilación a todos los empleados particulares del país,

\footnotetext{
130 Los proponentes fueron los diputados Pablo Aldunate, Humberto Abarca, Raúl Brañes, Ángel Faivovich, Roberto Gutiérrez, Juan de Dios Reyes, Marcelo Ruiz Solar, Julio Pereira Larraín, Humberto Yáñez. Ver: DSCD, Sesión 19 Ordinaria, 8 de julio de 1948, pp. 753-762.

131 DSCD, Sesión 19 Ordinaria, 19 de julio de 1950, p. 856.

132 DSCD, Sesión 9 Extraordinaria, 27 de noviembre de 1950, pp. 564 - 570.

133 "Jubilación de los empleados particulares", Panorama Económico, N45, diciembre de 1951, pp. 584 - 585.

134 "Jubilación de los empleados particulares", Panorama Económico, №45, diciembre de 1951, p. 585.
} 
el informe de la Comisión de Hacienda [de los Diputados] demostró la imposibilidad de financiar ese beneficio"135. La tensión se resolvió en las Comisiones de Hacienda y de Trabajo y Previsión Social del Senado donde "con la colaboración del señor Ministro de Salubridad y asesorada por el señor Director General de Previsión, don Julio Bustos, y por el Jefe de la Sección Actuarial de dicho Servicio, don Rolando González", se "llegó a una fórmula de previsión integral para los empleados particulares", a partir del informe presentado por el Director General de Previsión que dio "su aceptación técnica después de (el proyecto) ser encuadrado financiera y actuarialmente por los Servicios a su cargo" ${ }^{136}$. Finalmente, la decisión de las referidas comisiones señaló que:

“... el sistema que se propone comprende un campo de aplicación general para todos los empleados particulares sobre la base de un régimen mixto, con ... Coexistencia de un régimen de reparto para el pago de pensiones con un régimen de capitalización para los Fondos de Retiro e Indemnización" ${ }^{137}$.

Luego, el gobierno planteó indicaciones al texto aprobado en el Congreso, cambios que fueron aceptados tanto por la Cámara, como por el Senado. El proyecto fue aprobado como Ley №10.475 y promulgado el 28 de agosto de 1952. Concedía el derecho a pensión de invalidez, antigüedad, vejez, viudez, orfandad y cuota mortuoria o a retiro de fondos a los afiliados a la Caja de Previsión de Empleados Particulares o a organismos auxiliares.

Las reformas a la Caja del Seguro Obligatorio y a la Caja de Empleados Particulares fueron "la base de la reforma integral del Seguro Social de Chile" en el gobierno del presidente González. Satisfecho con ese logro, éste en su último mensaje ante el Congreso Pleno señaló:

"Puede afirmarse que esto constituye un paso trascendental en materia de previsión social, porque permitirá orientar la acción de las instituciones que la sirven, en un sentido más lógico, de mayor beneficio para las poblaciones aseguradas, siempre dentro de rigurosos conceptos de resguardo y cuyos planteamientos responden a realidades y no a simples especulaciones apoyadas en hipótesis irrealizables.

Es difícil señalar con precisión las repercusiones en todo lo benéfico que importa esta reforma ..." ${ }^{138}$.

La reforma de la Caja del Seguro Obligatorio, que dio origen al Servicio del Seguro Social y al Servicio Nacional de Salud, y la de la Caja de Empleados Particulares, se dio en un contexto de posguerra mundial, de expansión de la idea de universalidad en la seguridad social, a partir de

\footnotetext{
135 “Jubilación para empleados", Panorama Económico, N47, enero de 1952, p. 25.

${ }^{136}$ DSS, Sesión 18 Ordinaria, 9 de enero de 1952, p. 754.

137 DSS, Sesión 18 Ordinaria, 9 de enero de 1952, p. 755.

138 Mensaje de S.E. El Presidente de la República, don Gabriel González Videla, al Congreso Nacional al inaugurar el período ordinario de sesiones, 21 de Mayo de 1952, pp. 666 - 667.
} 
la experiencia británica del Plan Beveridge, y en el que 1952 fue un año de elecciones presidenciales, todo lo cual habría generado un ambiente más propicio para reformar la previsión.

\section{Reformas fallidas: 1955, 1962 y 1968}

Solo tres años después de la reforma de 1952, la previsión chilena era sujeta de un severo escrutinio y crítica desde el punto de vista de la equidad y su efecto sobre la economía. Ello llevó a tres gobiernos seguidos, de distinto signo político, a intentar reformas.

Ya en 1955 el presidente Ibáñez señalaba que "es preciso reconocer que (la previsión) adolece de defectos serios, tales como las desigualdades y privilegios existentes, beneficios excesivos y aún rayanos en el abuso, como las jubilaciones múltiples y exageradas" ${ }^{139}$. De modo similar, la Misión Klein-Saks, que había sido contratada "para asesorar al gobierno en materias de política económica", expuso que "la Seguridad Social del país necesita una revisión general" y que había "un exceso de Cajas para diversos grupos específicos, a menudo muy pequeños, lo que ha contribuido a aumentar los gastos de administración y ha creado una virtual anarquía con respecto a las diferencias registradas en imposiciones y beneficios" ${ }^{\prime 14}$.

Basada en los informes de la Misión Klein Saks, en diciembre de 1955, la administración Ibáñez presentó el "Programa Anti-inflacionista" ${ }^{141}$ orientado a enfrentar la permanente y creciente alza del costo de la vida. El gobierno también presentó una reforma al sistema previsional que buscaba enfrentar dos grandes problemas: "1ㅇ) La multiplicidad de regímenes e instituciones; y 2ㅇ) Los excesos de beneficios". Estos se concentraban "casi exclusivamente en el sector público" y dado que "varios de ellos (los beneficios) deben ser financiado directamente por el Erario Nacional, la carga que este soporta constituye un rubro de creciente importancia en el Presupuesto Fiscal"142. Ibáñez además señalaba que "el resultado final de los excesos jubilatorios ha sido formar una masa de pasivos que, en gran proporción, está compuesta por personas en plena capacidad de trabajo, lo que constituye un hecho que moral y económicamente no puede aceptarse" ${ }^{143}$.

\footnotetext{
139 Mensaje de S.E. El Presidente de la República, don Carlos Ibáñez del Campo, al Congreso Nacional al inaugurar el período ordinario de sesiones, 21 de Mayo de 1955, p. XI. El paréntesis es nuestro.

${ }^{140}$ Couyoumdjian, Juan Pablo. 2011. "Anexo: Las ideas de la Misión Klein \& Saks sobre el futuro económico de Chile", en Couyoumdjian, Juan Pablo (ed.), Reformas Económicas e Instituciones Políticas: la experiencia de la Misión Klein \& Saks en Chile, Santiago, Universidad del Desarrollo, pp. 271 - 272.

${ }^{141}$ Couyoumdjian, Juan Pablo. 2011. “¿Por qué la Misión Klein-Saks? Los orígenes de un programa de estabilización económica para Chile", en Couyoumdjian, Juan Pablo (ed.), Reformas Económicas e Instituciones Políticas: la experiencia de la Misión Klein \& Saks en Chile, Santiago, Universidad del Desarrollo, p. 91.

142 DSCD, Sesión 23 Extraordinaria, 6 de diciembre de 1955, pp. 1605 - 1606.

${ }^{143}$ DSCD, Sesión 23 Extraordinaria, 6 de diciembre de 1955, p. 1606.
} 
Luego de intensas negociaciones, el Programa Anti-inflacionista ${ }^{144}$ fue aprobado en el Congreso, convirtiéndose en la ley $12.006^{145}$, y con ello, en el período 1956 - 1957, el "remolino inflacionario" perdió gran impulso, aunque no se frenó ${ }^{146}$. Aun así, en un ambiente de crisis política, dificultades económicas, agudizadas por la inflación, y fuerte tensión entre el Gobierno y el Congreso, la reforma previsional no logró tener el respaldo político necesario y al término del mandato ésta aún estaba en trámite. Así, en su última cuenta pública ante el Congreso, el presidente Ibáñez reiteró "la necesidad de dar urgencia al proyecto que limita los excesos de la previsión, para eliminar los abusos y demasías y reducir el costo excesivamente alto de algunos regímenes previsionales" ${ }^{147}$.

El siguiente gobierno también intentó reformas el sistema previsional. En su primer mensaje ante el Congreso Pleno, el presidente Alessandri Rodríguez planteó el tema en los mismos términos que su antecesor:

"Como lo he expresado reiteradamente, el costo de administración de los servicios previsionales, del mismo modo que los gastos públicos, ha experimentado un crecimiento que no guarda relación alguna con el aumento de la población ni con el de la producción nacional, lo cual ha traído como consecuencia, que el país no pueda solventar esos gastos con una tributación normal.

Este estado de cosas ... ha sido la consecuencia de la multiplicidad de organismos y sistemas, cuya creación y posteriores reformas son el fruto de la presión ejercida por los sectores más influyentes de asalariados. Son estos grupos, los que han logrado así beneficios mayores que otros grupos, todo lo cual en definitiva, se ha traducido en una previsión más onerosa y en las explicables pugnas de los grupos que se han sentido postergados" ${ }^{148}$.

Acto seguido, el presidente reiteró la necesidad de avanzar en la reforma integral al sistema previsional. Para ello conformó una Comisión de Reforma de la Seguridad Social, presidida por Jorge Prat Echaurren, quien había sido ministro de Hacienda del presidente Ibáñez. La Comisión Prat, como comúnmente se le llamó, estuvo compuesta por una variedad de técnicos, asesores,

\footnotetext{
${ }^{144}$ Edwards denomina a este como "Programa de Estabilización". Ver: Edwards, Sebastián. 2011. "Estableciendo credibilidad: el rol de los consultores extranjeros en el Programa de Estabilización de 1955-1958 en Chile", en Couyoumdjian, Juan Pablo (ed.), Reformas Económicas e Instituciones Políticas: la experiencia de la Misión Klein \& Saks en Chile, Santiago, Universidad del Desarrollo, pp. 103-164. Couyoumdjian y Edwards coinciden en señalar que el foco de la propuesta era limitar los reajustes salariales de 1956 a un 50\% de la inflación pasada.

145 Couyoumdjian. 2011, “¿Por qué?”, p. 92; Edwards. 2011, “Estableciendo credibilidad”, p. 129.

146 Hirschman, Albert. 1964. Estudios sobre política económica en América Latina. En ruta hacia el progreso, Madrid, Aguilar, pp. 228 - 233.

${ }^{147}$ Mensaje de S.E. El Presidente de la República, don Carlos Ibáñez del Campo, al Congreso Nacional al inaugurar el período ordinario de sesiones, 21 de Mayo de 1955, p. 159.

148 Mensaje de S.E. El Presidente de la República, don Jorge Alessandri Rodríguez, al Congreso Nacional al inaugurar el período ordinario de sesiones, 21 de Mayo de 1959, p. 101.
} 
académicos y funcionarios que, entre 1959 y 1962, elaboraron 13 informes y prepararon una propuesta de reforma ${ }^{149}$. Concluyó que el esquema de seguridad social chileno estaba "condenado a desplomarse por injusto, por oligárquico, por discriminatorio y por ser ineficazmente oneroso, tanto para los ganadores de sueldos o salarios como para la producción nacional" ${ }^{150}$.

Las elecciones parlamentarias de 1961 generaron un significativo revés para las aspiraciones gubernamentales de lograr reformar la seguridad social. La coalición que respaldaba a Alessandri Rodríguez no logró alcanzar los votos suficientes para controlar, al menos, un tercio del Congreso y con ello poder imponer el veto presidencial en la discusión sobre la ansiada reforma ${ }^{151}$. Esto implicó que, finalmente, el gobierno no enviara a trámite legislativo su proyecto de reforma a la seguridad social en base a lo realizado por la Comisión Prat, dado que no lograría el respaldo político necesario. De este modo, un desilusionado Alessandri, en su penúltimo mensaje ante el Congreso Pleno, exponía sobre la imposibilidad de concretar una reforma previsional y el papel del Congreso y grupos de presión en ello:

"Ha sido uno de mis más hondos anhelos de ciudadano y gobernante procurar corregir las inequidades que contempla nuestro frondoso sistema previsional. Con profundo dolor y desengaño debo declarar que temo no poder lograrlo. Cuando asumí la presidencia prevalecía en el Congreso el criterio de que correspondía al Primer Mandatario la iniciativa en materia previsional. Desgraciadamente la $\mathrm{H}$. Cámara de Diputados tomó un acuerdo en sentido contrario y desde entonces se han multiplicado las iniciativas en esta materia que cada día crean nuevas distorsiones que harán más difícil una reforma. Los vetos que he formulado sobre el particular, ordinariamente han sido rechazados.

Mientras una reforma constitucional no prive en absoluto al Parlamento de iniciativa en materias previsionales, resultaría estéril el esfuerzo desplegado para realizar una reforma en la materia porque después de despachada, comenzaría a ser vulnerada bajo presiones de

\footnotetext{
${ }^{149} \mathrm{El}$ detalle de todos los nombres que participaron en la Comisión se puede encontrar en una carta enviada por Jorge Prat a Jorge Alessandri luego de terminado el trabajo de dicha instancia. Entre algunos nombres que se puede destacar están Rolando Gonzáles Bustos, Superintendente de Seguridad Social, Héctor Humeres Magnan, Fiscal de la Contraloría General, Jorge Álvarez Andrews, Jorge Briceño Warner, Luis Orlandini Molina, Ricardo Sáenz Ávila, Rubén Pozo Flores, entre muchos otros. Ver: Carta de Jorge Prat a Arturo Alessandri, (s/f), Archivo Jorge Alessandri Rodríguez, pp. 2-3.

${ }^{150}$ Comisión de Estudios de la Seguridad Social. 1964. Informe sobre la Reforma de la Seguridad Social Chilena. Tomo I, Santiago, Editorial Jurídica de Chile, p. vii.

${ }^{151}$ Carrasco, Camilo. 2009. Banco Central de Chile, 1925-1964. Una Historia Institucional, Santiago, Banco Central de Chile, p. 391; Correa, Sofía, Figueroa, Consuelo, Jocelyn-Holt, Alfredo, Rolle, Claudio y Vicuña, Manuel. 2000. Historia del Siglo XX Chileno. Balance Paradojal, Santiago, Editorial Sudamericana, p. 209.
} 
grupos interesados en obtener ventajas invocando toda clase de pretextos como hoy ocurre" ${ }^{152}$.

En el gobierno siguiente, el presidente Frei Montalva retomó los esfuerzos por una reforma integral al sistema de seguridad social. Para Frei Montalva, "la multiplicidad, disparidad, privilegios, omisiones e injusticias del actual sistema no sólo constituyen un factor permanente de malestar y perturbación, sino que son un obstáculo al logro de los planes de desarrollo económico y de reformas sociales que son parte de nuestro programa de gobierno, ... Este sistema llevará inevitablemente a la quiebra de las Cajas de previsión o a la insolvencia del país"153.

Aunque Frei había expuesto ante el Congreso Pleno su decidida intención de acometer la reforma previsional, su ambicioso programa de gobierno que incluía otras iniciativas que también le demandarían considerable capital político, como la reforma agraria, la chilenización del cobre, la reforma educacional y planes de estabilización monetaria y desarrollo económico, le llevaron a lanzar la reforma de la seguridad social al cuarto año de su mandato. En septiembre de 1968 el gobierno envió al Congreso el proyecto de reforma prometido, en el que señalaba estar "consciente de la crisis de nuestro régimen previsional". Agregaba que: "Mucho se ha dicho y hablado acerca del problema previsional de Chile. Se está de acuerdo, unánimemente, que él es malo. Voces de los más distintos y antagónicos credos políticos así lo han proclamado. Los diversos técnicos lo han reconocido" ${ }^{154}$. En el mismo mensaje exponía que:

"No se trata propiamente de un sistema de seguridad social. Todo es asistemático en nuestro régimen previsional. Él ha sido el producto de innumerables cuerpos legislativos, que ya exceden el número de $600, \ldots$ sin ninguna visión de conjunto. Tales cuerpos legales han dado origen a aproximadamente 30 sistemas diferentes de pensiones de antigüedad, más de 30 regímenes diferentes de pensiones de invalidez y 31 sistemas de pensiones de vejez, todos ellos distintos entre sí, y en todas cabe observar toda clase de discriminaciones, privilegios e injusticias irritantes.

Hay regímenes en donde basta 10 años de imposiciones para poder tener derecho a previsión, los que han originado jubilados con menos de 30 años de edad. Es inaceptable que un joven de 29 años de edad tenga la calidad de jubilado. Existen dentro del sector público, pensiones cuyos montos exceden de los 10.000 escudos mensuales ...lo cual excede, en más de dos veces, los montos máximos de las pensiones que se pagan en Francia y en Alemania Federal, países ricos y desarrollados(...)

\footnotetext{
152 Mensaje de S.E. El Presidente de la República, don Jorge Alessandri Rodríguez, al Congreso Nacional al inaugurar el período ordinario de sesiones, 21 de Mayo de 1963, p. 402.

${ }_{153}$ Mensaje de S.E. El Presidente de la República, don Eduardo Frei Montalva, al Congreso Nacional al inaugurar el período ordinario de sesiones, 21 de Mayo de 1965, pp. 74 - 75.

${ }^{154}$ DSCD, Sesión 30 Ordinaria, 3 de septiembre de 1968, p. 3025 y 3027.
} 
Cabe agregar aquí que, incluso tratándose de un mismo instituto previsional, se observan serias deficiencias en el reparto que hace de sus ingresos entre sus propios imponentes" ${ }^{\prime 155}$.

Para el ministro de Hacienda de la época, el sistema de pensiones de ese entonces:

“... era absolutamente inequitativo. Los que tenían capacidad de mayor presión habían logrado mejores beneficios ${ }^{156}$.... Había sectores como los bancarios que podían jubilar a los 20 años de trabajo ${ }^{157}$, los hípicos podían jubilar a los 10 años, ... había el privilegio de las perseguidoras ${ }^{158}$, en el que la pensión de la persona que jubilaba perseguía el sueldo de su cargo durante toda la vida, [lo que se quería] ampliar para otros sectores" ${ }^{\prime 159}$.

Agrega que, para la década de 1960, el sistema de pensiones "estaba quebrado ... el déficit fiscal anual que se producía por el crecimiento del gasto previsional lo asumía el Estado ... este déficit previsional se financiaba con déficit fiscal, o sea emisión de dinero" ${ }^{160}$.

La propuesta del gobierno buscaba, por un lado, "establecer que todas las cajas de previsión otorguen pensiones bajo los mismos requisitos, por los mismos montos, calculadas sobre idénticos sueldos base, sujetas a los mismos procesos de reajuste o revalorización, etc.", y, por otro, "evitar que en un futuro próximo se llegue a una situación en que no será posible pagar las pensiones" 161 .

El gobierno tenía una fuerte oposición desde ambos lados del espectro político y una bancada parlamentaria con notorias divisiones. A ello se unía el hecho que una reforma previsional que uniformara el sistema de pensiones, que favorecía a los que tenían mayor

\footnotetext{
155 DSCD, Sesión 30 Ordinaria, 3 de septiembre de 1968, p. 3025.

156 Por ejemplo, los parlamentarios podían jubilar con dos periodos en el cargo de representación, les era aplicable la "perseguidora", podían reliquidar su pensión si eran electos nuevamente para un cargo de representación (Ley 12.566) y las viudas de los parlamentarios fallecidos o sus hijos, a falta de ésta, podían recibir un generoso montepío que se incrementaba de acuerdo a los "emolumentos imponibles asignados o que se les asignen en el futuro a los Diputados y Senadores" (Ley 16.229).

157 Los empleados públicos también podían jubilar con 20 años de trabajo, con 2030 avos del monto que resultare del cálculo de su pensión, y con 30 30avos si cumplía con 30 años de servicio. Si la persona que jubilaba estaba en el tope de su respectivo escalafón, el cálculo se hacía sobre el último sueldo imponible. Si no estaba en esa situación, entonces en cálculo se hacía en base a las 36 últimas remuneraciones imponibles, lo que llevaba comúnmente a incrementos del sueldo imponible en ese período con la finalidad de incrementar la pensión. Luego los empleados públicos podían seguir trabajando, rejubilar, continuar trabajando y obtener una nueva pensión luego. Ninguno de estos beneficios, como tampoco las perseguidoras estuvo disponible para los obreros y sectores pobres.

158 La pensión perseguidora "era el mecanismo mediante el cual las personas favorecidas se jubilaban con una pensión igual a su último sueldo, y luego esta se reajustaba conforme lo hiciera el sueldo que la originaba. Para lograr una perseguidora había que tener buenos contactos o pertenecer a algún sindicato poderoso y estratégico". Normalmente la "perseguidora" se asignaba a los cargos superiores de la administración civil y militar. Ver: Ibáñez, Adolfo. "Perseguidora", El Mercurio, Santiago, 22 de agosto de 2016. Recuperado de: http://www.economiaynegocios.cl/noticias/noticias.asp?id=282697 (Consultado el 20 de abril de 2021).

${ }^{159}$ Andrés Zaldívar Larraín, comunicación personal, 5 de abril de 2021, Santiago.

${ }^{160}$ Andrés Zaldívar Larraín, comunicación personal, 5 de abril de 2021, Santiago.

161 DSCD, Sesión 30 Ordinaria, 3 de septiembre de 1968, pp. 3028 - 3030.
} 
influencia política, afectaría sentidos intereses y encontraría enconadas oposiciones de quienes temían perder o disminuir beneficios si la reforma se aprobaba; como ya había ocurrido con los intentos de los dos gobiernos precedentes. En este contexto, pronto surgieron críticas al proyecto, por lo que el ministro de Hacienda, Andrés Zaldívar Larraín, creó una Comisión Tripartita conformada por representantes del gobierno, expertos del partido de gobierno (el Demócrata Cristiano) y representantes de trabajadores, que incluían a miembros de la Central Única de Trabajadores (CUT) y de diversas cajas de previsión ${ }^{162}$. Para generar un clima favorable al proyecto, el gobierno retiró la urgencia y estableció un plazo de tres meses al trabajo de la Comisión "para estudiar las reformas al sistema previsional vigente en todo el país" 163.

Aún con el despliegue de estos esfuerzos, la reforma al sistema de seguridad social no fue discutida en el Congreso ${ }^{164}$. Ante este resultado, en su último mensaje ante el Congreso Pleno, el presidente Frei Montalva expuso su desazón:

“Persiste en el país una tendencia desproporcionada a favorecer aspiraciones ilimitadas, acompañada por una carrera sin freno en el ofrecimiento de ventajas ...

Cada grupo, de acuerdo con su capacidad de presión, pretende exigir del país más de lo que este puede dar, sin importarle el bien común de la nación. Cada uno pretende obtener ventajas con desmedro de otros que no tienen la misma fuerza para negociar. Y siempre encuentran quienes apadrinen sus exigencias sectoriales en desmedro del bien colectivo (...)

Una de las manifestaciones más extremas de este proceso ... es lo que ocurre en el campo de la previsión, cuya reforma ... resulta más difícil de impulsar que la propia reforma agraria. Siendo Chile un pueblo joven, compuesto por jóvenes, se está organizando progresivamente el descanso prematuro y la seguridad y los privilegios obtenidos por ley ....

La conquista del poder se convierte en el supremo objetivo, bajo el supuesto que todo está permitido para lograrlo.

(...) contra la opinión de organismos técnicos insospechables, contra la opinión de quienes administran los Servicios, se han dictado leyes sin financiamiento y otorgados beneficios imposibles de solventar sanamente. Las observaciones formuladas por el Gobierno han sido inútiles y se está llevando a la quiebra al sistema ${ }^{165}$.

\footnotetext{
162 "Estudio de reforma previsional no debe exceder 90 días", El Mercurio, Santiago, 16 de octubre de 1968, p. 33; "Zaldívar aceptó comisión que discute proyecto previsional", El Siglo, Santiago, 4 de octubre de 1968, p. 6.

163 "Estudio de reforma previsional no debe exceder 90 días", El Mercurio, Santiago, 16 de octubre de 1968, p. 33.

${ }^{164}$ Sobre este tema, el exministro Zaldívar expone que "no hubo discusión (en el Congreso), porque no había mayoría para aprobarla, aunque hubo un gran debate en el país". Andrés Zaldívar Larraín, comunicación personal, 5 de abril de 2021, Santiago.

165 Sexto Mensaje del Presidente de la República de Chile, don Eduardo Frei Montalva, al inaugurar el período de Sesiones Ordinarias del Congreso Nacional, 21 de Mayo de 1970, pp. 80 - 81.
} 
En este contexto de tensión entre los poderes ejecutivo y legislativo, el presidente Frei Montalva logró aprobar en el Congreso, en Enero de 1970, en el último año de su mandato, una reforma constitucional que había presentado el 20 de Noviembre de 1964, a menos de un mes de asumir, y que concedía iniciativa exclusiva al presidente de la República en materia de legislación previsional ${ }^{166}$. La reforma constitucional entró en vigencia al período presidencial siguiente. Entre otras materias, establecía que:

“... corresponderá exclusivamente al Presidente de la República la iniciativa para ... establecer o modificar los regímenes previsionales o de seguridad social; para conceder o aumentar, por gracia, pensiones u otros beneficios pecuniarios, y para condonar las sumas percibidas indebidamente por concepto de ...pensiones de jubilación, retiro o montepío o pensiones de gracia" ${ }^{167}$.

El gobierno siguiente, del presidente Allende, anunció que la Unidad Popular (UP) se proponía "unificar, mejorar y extender el sistema de seguridad social" ${ }^{168}$. Aunque no se verificaron acciones con ese propósito durante ese mandato, en 1971 el gobierno otorgó un incremento del $66,7 \%$ de las pensiones y jubilaciones del Servicio de Seguro Social (SSS), pero a 1973 el valor promedio de las pensiones del Servicio del Seguro Social era menos de la mitad del valor real que tenían en $1971^{169}$.

El alto número de Cajas y de regímenes de beneficios fue una característica del sistema de pensiones de la vieja democracia chilena, cuestión que estuvo en el centro de la inequidad con la que lo identificaba la crítica de la época. Rengifo anota que, hasta la década de 1970, la previsión social promovió la inclusión, tendió a la universalidad, pero con un carácter segmentado y desigual ${ }^{170}$. A fines de la década de 1970 había en Chile 32 Cajas de Previsión, con más de 100 regímenes previsionales distintos ${ }^{171}, 36$ Cajas operaban en la segunda mitad de la década de $1960^{172}$ y a 1941 existían 44 Cajas de Previsión ${ }^{173}$, en las que existían una multiplicidad de regímenes que concedían beneficios diferenciados a sus propios afiliados, según el tipo de trabajadores a los que pertenecían.

\footnotetext{
166 En 1943, mediante la Ley №7.727, se había aprobado una reforma constitucional que también limitaba la iniciativa parlamentaria en materia de gasto público.

167 Sexto Mensaje del Presidente de la República de Chile, don Eduardo Frei Montalva, al inaugurar el período de Sesiones Ordinarias del Congreso Nacional, 21 de Mayo de 1970, p. 2.

168 Programa Básico de Gobierno de la Unidad Popular. 1969. Candidatura Presidencial de Salvador Allende, Santiago, p. 26.

169 Arellano. 1988, políticas sociales, p. 79.

170 Rengifo Streeter, Francisca. 2018. "El Estado de seguridad social chileno y la institucionalización desigual del bienestar"; en Iván Jaksic y Francisca Rengifo (Editores), "Historia Política de Chile, 1810-2010", Tomo II Estado y Sociedad, Santiago, Chile, FCE y Universidad Adolfo Ibáñez.

171 Cheyre. 1988, La previsión, p. 28 y 178.

172 Andrés Zaldívar Larraín, comunicación personal, 5 de abril de 2021, Santiago.

173 Campos. 1941, Hacia una, p. 34.
} 
Así, la cuestión que sigue respecto de estos intentos reforma es por qué tres sucesivas administraciones, de orientación política diversa, que establecieron un diagnóstico común acerca de la gravedad del problema y a cuyo enfrentamiento dispusieron los recursos técnicos y políticos de sus gobiernos, no lograron reformar el sistema previsional ${ }^{174}$.

\section{Discusión}

El análisis de la evolución de los esquemas que rigieron las materias previsionales en la vieja democracia chilena deja ver característica acerca de cómo se desarrolló el proceso de la política pública en cada caso de creación o reforma de mecanismos de retiro, jubilatorio o seguro social.

Primero, dadas las definiciones institucionales establecidas en las constituciones que han regido en Chile -salvo el ensayo federalista de 1826-, que han establecido un sistema presidencial en el país, particularmente las de 1833 y de 1925, el presidente de la República aparece como el actor protagónico del proceso. Los criterios establecidos por O'Higgins y Francisco Antonio Pinto para conceder jubilaciones, la ley de 1832 y su reforma de 1857, la ley de retiro para miembros del Ejército y la Armada de 1839, la ley de recompensas militares de 1881, la ley 1.146 de 1898, la creación de la Caja de Ahorros de los empleados de Ferrocarriles en 1911 y sus reformas, la creación y reformas de las Cajas de Previsión a partir de 1924, e incluso los intentos fallidos de reforma de 1955, 1962 y 1968, y la reforma constitucional de 1970, muestran la fuerte incidencia de la motivación y voluntad presidencial en la formulación de política pública.

Aunque la concreción de iniciativas de política pública que se expresan a través de ley requiere la concurrencia del Congreso en cada uno de los casos, el uso de atribuciones institucionales, el ejercicio del liderazgo presidencial y la aplicación de mecanismos informales de poder y persuasión han normalmente permitido al poder ejecutivo alcanzar un rol de alta incidencia en la formulación de políticas públicas que estas líneas destacan. Incluso en los sucesos de 1924-1925, que dan origen al sistema de Cajas de Previsión, es el poder ejecutivo, con el presidente licenciado y el Congreso suspendido, el que finalmente decide e instala el sistema que, desde entonces se irá desarrollando y abultando durante las siguientes cinco décadas y media.

Segundo, los depositarios del conocimiento específico y operativo del funcionamiento del Estado, la Administración Pública y el problema a intervenir, comúnmente identificados como "técnicos" y actualmente denominados como "tecnócratas", han jugado en cada tiempo un rol preponderante en el diseño de la propuesta de intervención. Aunque los casos revisados

\footnotetext{
${ }^{174}$ Las reformas no fueron rechazadas, como tal en el Congreso. Un académico estudioso del sistema previsional en la época señala que las reformas "no se rechazaron, no se les puso urgencia y (dada la falta de apoyo) los presidentes desviaron su atención hacia otros temas con las urgencias". Eduardo Aninat Ureta, comunicación personal, 4 de marzo de 2021, Santiago.
} 
muestran que el debate político puede generar modificaciones a las propuestas iniciales (por ejemplo, en las reformas de 1952), especificar énfasis y orientaciones generales, el peso del conocimiento concreto de los temas y el razonamiento aportado por los tecnócratas juegan un rol determinante en la forma y contenidos que adquiere finalmente la política pública.

La revisión de casos también muestra que es el poder ejecutivo, regularmente el presidente, con la excepción de los sucesos de 1924-1925, el que asigna y empodera a un grupo de tecnócratas el análisis del problema y el diseño de la intervención que se proyecta. Incluso, en el caso de iniciativas que surgieron desde la sociedad civil, como en el proceso de creación de la Caja de Empleados Particulares, o de alternativas, adicionales a las del Ejecutivo, que surgieron desde el Parlamento, como aquella del Senador Yáñez sobre creación de la Caja de Empleados Públicos, estas finalmente entran en un diálogo y ajuste técnico y político con el poder ejecutivo para darle viabilidad y espacio en la agenda legislativa de gobierno.

Tercero, la exposición de los casos también muestra que, en la selección de problemas a intervenir, los criterios generales de intervención se dan en círculos circunscritos a actores políticos del Estado y a grupos de interés estrechamente conectados con ellos. En este contexto, son los promotores de temas y alternativas de intervención los que amplían las redes políticas hacia grupos de interés involucrados en el problema que será intervenido, con la finalidad de generar presión sobre los tomadores de decisiones en los poderes públicos y, de ese modo, lograr que la política pública que finalmente se implemente sea lo más cercana posible a sus intereses o expectativas.

El modo en que se dio el proceso que llevó al surgimiento de la Caja de Empleados Particulares en 1924, la de Empleados Públicos en 1925, los cuerpos legales que dieron origen a una proliferación de Cajas y regímenes previsionales a lo largo del siglo XX, así como las iniciativas que concedían jubilaciones a empleados públicos y retiro a personal militar en el siglo XIX coincide con lo que Cobb, Ross y Ross denominan como "modelo de iniciativa interna" de la agenda formal de política pública o de la agenda de actores del Estado ${ }^{175}$.

En estos casos, la identificación y visibilización del problema previsional y el surgimiento de propuestas de intervención se dio en esos estrechos círculos, en conexión con grupos de interés con capacidad de presión e influencia sobre los poderes públicos. Así, la revisión de los casos sugiere la existencia de una relación clientelar ${ }^{176}$ en el surgimiento y desarrollo del sistema

\footnotetext{
175 Cobb, Ross \& Ross. 1976, "Agenda Building”.

${ }^{176}$ Aunque no hay una definición única de clientelismo, los elementos que reiteradamente se mencionan acerca de este concepto hacen referencia a la distribución de beneficios a grupos específicos de la población como retribución al apoyo electoral recibido o esperado, a una alianza o vinculación entre quien tiene el poder de acceder a recursos públicos o decidir sobre su distribución, normalmente denominado el patrón, y quien espera ser beneficiado por las decisiones de ese patrón, dado el apoyo electoral entregado, normalmente denominado como el cliente. Ver, por ejemplo: Stokes, Susan. 2009. "Political Clientelism", en Goodin, Robert E., The Oxford Handbook of Political Science, Oxford, Oxford University Press, pp. 648-672; Moreno, Javier. 1999. "El clientelismo político: historia de un concepto multidisciplinar”, en Revista de Estudios Políticos (Nueva Época), n¹05, Madrid, pp. 73-95; Landé, Carl. 1977.
} 
previsional de la vieja democracia chilena, donde los actores políticos promovían esquemas de retiro, pensión y jubilaciones que favorecían a grupos específicos conectados con ellos. La práctica clientelar que llevaba al establecimiento de esquemas previsionales queda expuesta en el Mensaje del presidente Frei Montalva al Congreso con motivo de la presentación de la reforma constitucional aprobada mediante Ley №17.284. En el mensaje exponía que:

“... otros de sus fundamentos [para la reforma constitucional] es liberar al Parlamento de los bloques de presión que actúan sobre él, desde distintos niveles y que tienden a obtener normas legales de excepción, que producen un desquiciamiento y anarquía de los planes de acción y sistemas prestablecidos. [Además] cada gremio y los grupos de presión que ellos representan actúan sobre las fuerzas políticas representadas en el Parlamento y tienen y han llegado a obtener regímenes de excepciones que paulatinamente provocan una anarquía en el sistema" ${ }^{177}$.

De este modo, el mismo modelo de construcción de la agenda formal de políticas públicas, que llevó al establecimiento, desarrollo y evolución del sistema previsional de la vieja democracia chilena, generó las condiciones para el fracaso de los intentos de reforma de 1955, 1962 y 1968, dado el desarrollo de un enjambre clientelar de intereses entre parlamentarios y grupos de presión que tres presidentes no lograron superar. Ibáñez, Alessandri Rodríguez y Frei Montalva abogaron, sin éxito, por terminar un régimen altamente desigual y moldeado por la acción de grupos de presión.

Las tres características del proceso de formulación de políticas públicas en la previsión de la vieja democracia chilena dejan ver como su interacción van determinando el curso del proceso y el resultado a que arriba. En los casos exitosos, la motivación y liderazgo presidencial, el rol de tecnócratas empoderados y su capacidad de articular intereses se muestran como factores de éxito para que el proceso de formulación de la política pública arribara a la meta deseada. Pero, ello también fue generando precedentes, satisfaciendo intereses particulares y cristalizando beneficios que intentos posteriores, por imprimir mayor racionalidad a la acción del Estado en este campo y equidad en la distribución del bien previsional, no lograron concretar aún con las mismas atribuciones institucionales y empeño presidencial, y el despliegue tecnocrático de los casos exitosos. De este modo, el enjambre de intereses ${ }^{178}$ que

\footnotetext{
"Introduction: the dyadic basis of clientelism", in Schmidt, Steffen, Scott, James, Landé, Carl \& Guasti, Laura (eds.), Friends, Followers and Factions: A Reader in Political Clientelism, Berkeley, Los Angeles, University of California Press, pp. xiii-xxxvii.

177 DSCD, Sesión 26 Extraordinaria, 9 de abril de 1969, pp. 2695 - 2696.

178 Sobre este tema, Rengifo anota que grupos de trabajadores que tuvieron mayor capacidad organizativa desarrollaron negociaciones con partidos políticos, gobierno y el Estado que les permitieron obtener mayores y mejores prestaciones y resistir "a las reformas universalistas que amenazaban con hacerles perder o disminuir sus beneficios ya adquiridos. Ver: Rengifo. 2018, "El Estado de seguridad social chileno", p.422.
} 
se articulan en torno a la previsión aparece como una variable central en la explicación de éxitos y fracasos de creación y reforma de políticas públicas en este ámbito de acción del Estado.

\section{Palabras al cierre}

El análisis de la evolución de la previsión de la vieja democracia chilena ha identificado características centrales en el proceso de formulación de políticas públicas de este sector de actividad. No obstante que desde inicios de la República se fueron implementando esquemas jubilatorios para el personal del Estado, la falta de mecanismos similares para los trabajadores no estatales llevó a estos - particularmente desde mediados del siglo XIX-a generar iniciativas propias de ayuda mutua frente a los momentos de necesidad. Aunque estos mecanismos de socorro fueron útiles ante la ausencia de esquemas de ayudas sociales institucionales, su establecimiento como política pública requería la intervención de los poderes públicos. De este modo, en el contexto de un régimen político presidencial, en que prevalece un modelo de iniciativa interna de construcción de la agenda estatal de políticas públicas, la motivación y liderazgo presidencial, unido al empeño tecnocrático aparecen como elementos claves en la decisión aprobatoria de iniciativas de política pública, pero el mismo modelo de construcción de la agenda, en el caso estudiado, llevó a establecer la imposibilidad de introducir reformas que tres sucesivos gobiernos promovieron.

El estudio sugiere que las prácticas clientelares que estuvieron presentes en la evolución del sistema previsional también estuvieron presentes en el fracaso de los intentos de reforma. Ello abre nuevas avenidas de investigación. Dado que los estudios del proceso de formulación de políticas públicas tienden a centrarse en casos de procesos que terminan en aprobación de propuestas de creación o reforma de políticas públicas, el análisis de reformas fallidas permite indagar acerca de la combinación de impulsos y obstáculos que llevó a la imposibilidad de reformas. También permite identificar si los hallazgos a que se arribó en este estudio son propios del ámbito previsional, donde hay explícitos intereses en juego, o si ello también está presente en otros campos de la actividad estatal.

\section{Referencias citadas}

\section{Fuentes}

Biblioteca del Congreso Nacional. 2020. Historia de la Ley 10.383, Santiago.

Boletín de la Oficina del Trabajo (Santiago, 1918 1921).

Carta de Jorge Prat a Arturo Alessandri. (s/f). Archivo Jorge Alessandri Rodríguez. 
Comisión de Estudios de la Seguridad Social. 1964. Informe sobre la Reforma de la Seguridad Social Chilena. Tomo I, Santiago, Editorial Jurídica de Chile.

Consejo Nacional de Economía. (s/f). Informe de la Comisión del Trabajo Salarios y Previsión Social del Consejo Nacional de Economía, sobre el Proyecto de Reforma a las Leyes 4054 y 4055, Santiago, Consejo Nacional de Economía, Secretaría General.

Diario de Sesiones del Senado de Chile (1820, 1829, 1918, 1914, 1921, 1922, 1951, 1952).

Diario de Sesiones de la Cámara de Diputados de Chile (1856, 1881, 1892, 1893, 1898, 1914, 1923 , 1924, 1941, 1948, 1950, 1955, 1968, 1969).

Ejército de Chile, "Creación del Cuerpo de Inválidos de Santiago", 2020. Recuperado de https://www.ejercito.cl/efemerides/efemerides/MTUz. (consultado el 30 de noviembre de 2020).

El Mercurio (1918, 1920, 1922, 1968, 2016), Santiago.

Entrevista a Andrés Zaldívar Larraín, comunicación personal, 5 de abril de 2021, Santiago.

Entrevista a Eduardo Aninat Ureta, comunicación personal, 4 de marzo de 2021, Santiago. La Nación (Santiago, 1922, 1924).

Leyes y Decretos de la República de Chile: Ley N¹.146 del 28 de diciembre de 1898, Ley 3.029 del 9 de septiembre de 1915, Ley N4059 del 8 de septiembre de 1924, Decreto Ley N454 del 15 de julio de 1925, DFL 857 del 11 de noviembre de 1925, Ley Nº10383 del 28 de julio de 1952.

Mensaje de S.E. El Presidente de la República al Congreso Nacional al inaugurar el período ordinario de sesiones (1952, 1955, 1959, 1963, 1965, 1970).

Panorama Económica (Santiago, 1948, 1951, 1952).

Programa Básico de Gobierno de la Unidad Popular. 1969. Candidatura Presidencial de Salvador Allende, Santiago.

República de Chile. 1855. Lei de Montepío Militar, Santiago, Imprenta Nacional.

República de Chile. 1958-1959. Repertorio de legislación y jurisprudencia chilenas: Código del Trabajo, Santiago, Editorial Jurídica.

Revista de la Beneficencia Pública (Santiago, 1922).

Sesiones de los Cuerpos Legislativos de la República de Chile, Comisión Nacional (1827).

\section{Bibliografía}

Ahumada, Daniel y Salas, Alejandro. 2018. "La participación de la Oficina del Trabajo en la configuración del sistema de previsión social chileno, 1909-1925", en Revista de Historia y Geografía, N³9, Santiago, pp. 73-97.

Alessandri, Arturo. (1967a). Recuerdos de Gobierno. Tomo I, Santiago, Editorial Nascimento. 
Aninat, Eduardo. 1971. Nuevas Alternativas para el Sistema Chileno de Seguridad Social, Documento CEPLAN №6, Santiago, Centro de Estudios de Planificación Nacional, Universidad Católica de Chile.

Arellano, José Pablo. 1988. Políticas Sociales y Desarrollo. Chile 1924-1984, Santiago, Chile, CIEPLAN. Barría, Diego. 2009. "En busca del mérito: la discusión académica en torno a los empleados públicos en Chile, 1884-1920", en Estudios Ibero-Americanos, vol.35, º2, Logroño, pp. 148-165.

Barría, Diego. 2015. “Empleados públicos y clase media, Chile 1880-1920: un análisis exploratorio a partir de cifras oficiales", en Revista de Historia y Geografía, N³2, Santiago, pp. 77-100.

Barzelay, Michael \& Gallego, Raquel. 2006. “From 'New Institutionalism' to 'Institutional Processualism': Advancing Knowledge about Public Management Policy Change", in Governance, № 4, vol. 19, Oxford, pp. 531-557.

Bennet, Juan Pablo. 1926. "La Revolución del 5 de Septiembre de 1924", Santiago, Chile, Barcells.

Campos Menéndez, Alfonso. 1941. Hacia una Política Preventiva de los Seguros Sociales, Universidad de Chile, Tesis para optar al grado de Licenciado en Ciencias Jurídicas.

Carrasco. Camilo. 2009. Banco Central de Chile, 1925-1964. Una Historia Institucional, Santiago, Banco Central de Chile.

Castiglioni, Rossana. 2000. Welfare State Reform in Chile and Uruguay: Cross-class coalition, elite ideology and veto players, XXII Congress of the Latin American Studies Association, Miami, March, pp. 16-18.

Castiglioni, Rossana. 2015. Building and sustaining social protection: cross-class coalition, elite responses, and party politics in Chile and Uruguay (1970-1973), Working Paper №407, Kellogg Institute for International Studies, University of Notre Dame.

Cheyre, Hernán. 1988. La Previsión en Chile Ayer y Hoy: Impacto de una Reforma, Santiago, Centro de Estudios Públicos.

Cobb, Roger, Ross, Jennie-Keith \& Ross, Marc. 1976. “Agenda Building as Comparative Political Process", in The American Political Science Review, N 1, vol. 70, Cambridge, pp. 126-138.

Correa, Sofía, Figueroa, Consuelo, Jocelyn-Holt, Alfredo, Claudio, Rolle y Vicuña, Manuel. 2000. Historia del Siglo XX Chileno. Balance Paradojal, Santiago, Editorial Sudamericana.

Couyoumdjian, Juan Pablo. 2011. “¿Por qué la Misión Klein-Saks? Los orígenes de un programa de estabilización económica para Chile”, en Couyoumdjian, Juan Pablo (ed.), Reformas Económicas e Instituciones Políticas: la experiencia de la Misión Klein \& Saks en Chile, Santiago, Universidad del Desarrollo, pp. 61-102.

Couyoumdjian, Juan Pablo. 2011. “Anexo: Las ideas de la Misión Klein \& Saks sobre el futuro económico de Chile", en Couyoumdjian, Juan Pablo (ed.), Reformas Económicas e Instituciones Políticas: la experiencia de la Misión Klein \& Saks en Chile, Santiago, Universidad del Desarrollo, pp. 255-281.

Dinator, Raúl. 2013. “La Previsión Militar desde el inicio de la emancipación hasta la creación de la Caja de Previsión de la Defensa Nacional”, en Anuario de la Academia de Historia Militar, № 27, Santiago. 
Donoso, Armando. 1934. "Conversaciones con don Arturo Alessandri", Santiago, Biblioteca Ercilla. Edwards, Sebastián. 2011. "Estableciendo credibilidad: el rol de los consultores extranjeros en el Programa de Estabilización de 1955-1958 en Chile", en Couyoumdjian, Juan Pablo (ed.), Reformas Económicas e Instituciones Políticas: la experiencia de la Misión Klein \& Saks en Chile, Santiago, Universidad del Desarrollo, pp. 103-164.

Flores, Eliodoro. 1919. Jubilación del Profesorado, Santiago, Imprenta Universitaria.

Garretón, Manuel Antonio y Morales, Eduardo. 1976. Políticas sociales y papel redistributivo del Estado en América Latina. Antecedentes y consideraciones preliminares, Documento de Trabajo FLACSO, Santiago, FLACSO.

Gerring, John. 2009. "The Case Study: What It Is and What It Does", in Goodin, Robert (ed.), The Oxford Handbook of Political Science, New York, Oxford University Press, pp. 1133-1165.

Grez, Sergio. 1994. "La trayectoria del mutualismo en Chile (1853-1990). Apuntes para su estudio", en Mapocho, №35, Santiago, pp. 293-315.

Grez, Sergio. 1995. La "cuestión social" en Chile. Ideas y debates precursores (1804-1902), Santiago, DIBAM.

Grez, Sergio. 2001. "El escarpado camino hacia la legislación social: debates, contradicciones y encrucijadas en el movimiento obrero y popular (Chile: 1901-1924)", en Cuadernos de Historia, $N^{\circ} 21$, Santiago, pp. 119-182.

Hinojosa. Francisco. 1967. El libro de Oro de los Empleados Particulares, Santiago, Editorial Nascimento.

Hinojosa. Francisco. 1967. La Caja de Previsión de Empleados Particulares. Génesis: cómo, cuándo y dónde surgió la iniciativa de su creación, Santiago, sin sello editorial.

Hirschman, Albert. 1964. Estudios sobre política económica en América Latina. En ruta hacia el progreso, Madrid, Aguilar.

Kingdon, John. 2011. Agendas, Alternatives, and Public Policies, Glenview, Illinois, LongmanPearson.

Landé, Carl. 1977. "Introduction: the dyadic basis of clientelism", in Schmidt, Steffen, Scott, James, Landé, Carl \& Guasti, Laura (eds.), Friends, Followers and Factions: A Reader in Political Clientelism, Berkeley, Los Angeles, University of California Press, pp. xiii - xxxvii.

Larrañaga, Osvaldo. 2010. "Las Nuevas Políticas de Protección Social en Perspectiva Histórica”, en Larrañaga, Osvaldo y Contreras, Dante (eds.). Las Nuevas Políticas de Protección Social en Chile, Santiago, Uqbar, pp. 13-42.

López, Elvira. 2014. El proceso de construcción estatal en Chile. Hacienda pública y burocracia (18171860), Santiago, Centro de Investigación Diego Barros Arana/DIBAM.

Mardones, Jorge. 1954. "La reforma de la seguridad social de los obreros. Motivos de la Ley 10.383", Santiago, Editorial Jurídica de Chile.

Méndez, Carlos. 2009. Héroes del silencio. Los veteranos de la Guerra del Pacífico, Santiago, Centro de Estudios Bicentenarios. 
Mesa-Lago, Carmelo. 1978. Social Security in Latin America. Pressure Groups, Stratification, and Inequality, Pittsburgh, University of Pittsburgh Press.

Mesa-Lago, Carmelo. 1985. El Desarrollo de la Seguridad Social en América Latina, Estudios e Informes de la CEPAL №43, Santiago, Naciones Unidas.

Molina, Julio. 1924. Creación de una verdadera Caja de Retiro y de Previsión Social para los Empleados Públicos Civiles, Santiago, Imprenta Universitaria.

Molina Bustos, Carlos. 2007. Una mirada historiográfica acerca del desarrollo de institucionalidad sanitaria chilena: 1889-1989, Universidad de Chile, Tesis para optar al grado de Magister en Historia.

Moreno, Javier. 1999. "El clientelismo político: historia de un concepto multidisciplinar", en Revista de Estudios Políticos (Nueva Época), № 105, Madrid, pp. 73-95.

Morris, James. 1967. Las elites, los intelectuales y el consenso: estudio de la cuestión social y del sistema de las relaciones industrials en Chile, Santiago, Editorial del Pacífico.

Peters, B. Guy. 2019. Institutional Theory in Political Science, Northampton, Massachusetts, Edward Elgar.

Peters, B. Guy, Pierre Jon \& S. King, Desmond. 2005. "The Politics of Path Dependency: Political Conflict in Historical Institutionalism", in The Journal of Politics, vol. 67, № 4, Chicago, pp. 12751300.

Pierson, Paul. 1996. "The path to European integration. A historical institutionalist analysis", in Comparative Political Studies, № 2, vol. 29, Newbury Park, pp. 123-163.

Pierson, Paul y Skocpol, Theda. 2008. "El institucionalismo histórico en la ciencia política contemporánea", en Revista Uruguaya de Ciencia Política, nN 1, vol. 17, Montevideo, pp. 7-38.

Poblete, Moisés. 1949. El derecho del trabajo y la seguridad social en Chile, Santiago, Editorial Jurídica de Chile.

Rengifo Streeter, Francisca. 2018. "El Estado de seguridad social chileno y la institucionalización desigual del bienestar", en Jaksic, Iván y Rengifo, Francisca (eds.), "Historia Política de Chile, 1810-2010", Tomo II Estado y Sociedad, Santiago, Chile, FCE y Universidad Adolfo Ibáñez.

Skocpol, Theda. 1995. "Why I am and Historical Institutionalist", in Polity, no 1, vol. 28, Chicago, pp. 103-106.

Stein, Ernesto, Tommasi, Mariano, Echeberría, Koldo, Lora, Eduardo y Payne, Mark (coord.). 2006. La política de las políticas públicas. Progreso económico y social en América Latina, Washington DC, Banco Interamericano de Desarrollo.

Steinmo, Sven. 2008. "What is Historical Institutionalism", en Della Porta, Donatella y Keatings, Michael (eds.), in Approaches in Social Sciences, Cambridge, UK, Cambridge University Press.

Stokes, Susan. 2009. "Political Clientelism", en Goodin, Robert E., The Oxford Handbook of Political Science, Oxford, Oxford University Press, pp. 648-672.

Thelen, Kathleen. 1999. "Historical Institutionalism in Comparative Politics", en Annual Review of Political Science, vol.2, Palo Alto, pp. 369-404. 
Trigo, Luis. 2016. "Una revisión de los aportes del Institucionalismo Histórico a la Ciencia Política”, en Revista Colombiana de Ciencias Sociales, № 1, vol. 7, Medellín, pp. 224-241.

Urzúa, Germán y García, Ana María. 1971. Diagnóstico de la Burocracia Chilena (1818-1969), Santiago, Chile, Editorial Jurídica de Chile.

Venegas, Fernando y Grez, Sergio. 2021. “Historiografía del mutualismo chileno, 1853-1990: análisis crítico y nuevas perspectivas", en Revista Izquierdas, № 20, Santiago, pp. 1-30.

Vergara, Felipe. 2021. "La organización obrera ferroviaria. Antecedentes, procesos y logros tras el desarrollo de las huelgas 1906-1923", en Revista Notas Históricas y Geográficas, N²4, Valparaíso, 273 - 319.

Wallich, Christine. 1981. Social security and savings mobilization. A case study of Chile, Domestic Finance Studies $N^{\circ} 67$, Washington D.C., The World Bank.

Wallich, Christine. 1983. Savings mobilization through social security. The experience of Chile during 1916-77, World Bank Staff Working Papers N553, Washington D.C., The World Bank.

Woolcock, Michael, Szreter, Simon \& Rao, Vijayendra. 2010. How and Why Does History Matter for Development Policy? Policy Research Working Paper №542, Development Research Group, Poverty and Inequality Team, Washington DC, The World Bank.

Yáñez, Juan Carlos. 2008. La intervención social en Chile, 1907-1932, Santiago, Ril Editores.

Zelada, Marco Aurelio. 1936. Aporte al conocimiento de la legislación social ferroviaria: Génesis de la Caja de Retiros y de Previsión Social de los Ferrocarriles del Estado, Santiago, Talleres Gráficos San Vicente. 